\title{
Using ELECTRE-TRI and FlowSort methods in a stock portfolio selection context
}

\author{
Mir Seyed Mohammad Mohsen Emamat ${ }^{*}$ (D), Caroline Maria de Miranda Mota², Mohammad Reza Mehregan ${ }^{3}$, \\ Mohammad Reza Sadeghi Moghadam ${ }^{3}$ and Philippe Nemery ${ }^{4}$
}

\author{
${ }^{*}$ Correspondence: \\ emamat@atu.ac.ir; \\ sm.emamat@gmail.com \\ ${ }^{1}$ Department of Industrial \\ Management, Faculty \\ of Management \\ and Accounting, Allameh \\ Tabataba'i University, \\ Tehran 14348-63111, Iran \\ Full list of author information \\ is available at the end of the \\ article
}

\begin{abstract}
In recent years, multi-criteria sorting problems have become an interesting topic for researchers working on multi-criteria decision-making. ELimination and Choice Expressing REality (ELECTRE)-TRI and FlowSort are well-known approaches suggested for such a classification. The current study aimed to implement ELECTRE-TRI and FlowSort methods in the stock portfolio selection (SPS) as one of the most popular and important decision-making subjects and compare the outcomes of each method to understand how these methods perform in SPS problems. In this study, the bestworst method was applied to determine the weights of criteria. Four approaches for ELECTRE-TRI and 15 approaches for FlowSort were considered. Finally, 19 different approaches were considered to select stocks from a large pool of stocks. Results indicated that the model parameter should be properly defined to minimize inconsistencies and improve the power of the model.
\end{abstract}

Keywords: Multi-criteria decision-making, ELECTRE-TRI, FlowSort, Best-worst method, Finance

\section{Introduction}

Currently, multi-criteria decision-making (MCDM) is an integral part of operations research and occupies a prominent position within the field owing to significant theoretical and practical developments during the past five decades. MCDM methods can provide the decision-maker (DM) with a countable number of alternative decisions with several criteria attached to each decision (Qu et al. 2018). MCDM can be considered a decision tool for helping DMs maximize their satisfaction (Vanani and Emamat 2019). In the past decades, many MCDM methods have been proposed, and the most popular methods are the analytic hierarchy process (AHP) (Saaty 1977, 1986, 1990), analytic network process (Saaty 1996), technique for order of preference by similarity to ideal solution (TOPSIS) (Hwang and Yoon 1981), VIseKriterijumska Optimizacija I Kompromisno Resenje (VIKOR) (Opricovic and Tzeng 2004), ELimination and Choice Expressing REality (ELECTRE) (Roy 1968, 1991), and Preference Ranking Organization METHod for Enrichment Evaluation (PROMETHEE) (Brans and Vincke 1985). party material in this article are included in the article's Creative Commons licence, unless indicated otherwise in a credit line to the material. If material is not included in the article's Creative Commons licence and your intended use is not permitted by statutory regulation or exceeds the permitted use, you will need to obtain permission directly from the copyright holder. To view a copy of this licence, visit http:// creativecommons.org/licenses/by/4.0/. 
Roy (1968) established the foundations of the MCDM outranking approach by developing the ELECTRE method. Since then, the outranking approach has been widely used by researchers. The outranking relation is a binary relation for representing the DM's preferences and is used to examine the strength of the preference of alternatives over each other. Outranking methods generally operate in two steps: developing outranking relations for all the alternatives and exploiting the outranking relations for choosing, sorting, or ranking alternatives (Xidonas et al. 2012). ELECTRE and PROMETHEE families are the main methods covered under the label of the outranking approach (Figueira et al. 2005). ELECTRE and PROMETHEE methods can deal with lack of information and some vagueness. However, the main advantage of PROMETHEE methods is that they are easy to use (Velasquez and Hester 2013).

The performance values of alternatives being affected by imprecision and inaccurate determination are not uncommon. Different solutions exist for modeling these phenomena, including probability distribution, confidence intervals, and fuzzy numbers. However, the concept of pseudo criterion and its two thresholds (indifference and preference thresholds), known in the outranking approach, allow these phenomena to be considered (Roy et al. 1986; Takeda 2001).

Roy (1981) identified four types of decision problems: choice, sorting, ranking, and description problems (Ishizaka and Nemery 2013). Among these problems, the sorting problems aim to assign alternatives to predefined homogenous groups by considering different criteria. Sorting problems have numerous applications, for instance, medicine (Belacel 2000; Belacel and Boulassel 2004), human resources (Gomes and Santos 2008; Pereira and Mota 2016), sustainability analysis (Silva et al. 2014a), location analysis (Silva et al. 2014b), finance and economics (Verheyden and De Moor 2014; Doumpos et al. 2016), risk (Shen et al. 2016; Certa et al. 2017), supply chain management (Govindan and Jepsen 2016; Silva and Sobral 2017), project management (Micale et al. 2019b; de Araújo et al. 2021), and warehouse management (Micale et al. 2019b). For solving multi-criteria sorting problems, ELECTRE-TRI (Yu 1992) extends the ELECTRE family, and FlowSort (Nemery and Lamboray 2008) is an extension of the PROMETHEE family. ELECTRETRI is the most frequently used sorting method based on the outranking approach (Doumpos and Zopounidis 2002).

In real-life decision-making, DMs consider multiple criteria (Kou et al. 2021), and as a popular approach in decision-making, the use of MCDM is increasing. However, the development of numerous MCDM methods has been faced with several criticisms. The main question is, "Do we have a greater need for developing new methods or for evaluating the accuracy of existing methods?".

Roy and Bouyssou (1993) believed that, although the diversity of MCDM methods is a strong point, such diversity can also be a weakness. Deciding whether a certain method makes more sense than the other in a specific problem situation is challenging (Ishizaka and Nemery 2013). Doumpos and Zopounidis (2002) stated that, despite the significant theoretical developments of MCDM classification methodologies, studies on the efficiency of these methodologies are still sparse.

Capital market investment is a growing stream in the economic literature (Gupta et al. 2019). In this study, two multi-criteria sorting methods, ELECTRE-TRI and FlowSort, have been applied to form the stock portfolio. These methods are well adapted to the 
nature of the stock portfolio selection (SPS) problem, as they consider conflicting and multiple criteria in the analysis. Classic portfolio models could not consider more than two criteria. However, presently, many investors prefer to consider additional criteria. In addition, the formation of a stock portfolio is a sorting problem, so multi-criteria sorting methods are very suitable for this type of problem. Multi-criteria sorting methods assign alternatives to classes by comparing alternatives with reference profiles. The stock portfolio can be formed easily using this process. ELECTRE and PROMETHEE families of methods are very popular in MCDM and have been applied successfully in several studies. ELECTRE-TRI and FlowSort are sorting methods belonging to ELECTRE and PROMETHEE families, respectively.

One of the advantages of multi-criteria sorting methods over clustering methods is that, in multi-criteria sorting methods, the order of groups is clear. Thus, the first group always contains the best alternatives, while the last group always contains the worst. Multi-criteria sorting methods are adapted to the nature of the SPS problem as the first group can be a stock portfolio. In clustering methods, the priority between groups is unspecified. Therefore, after clustering, determining the order of groups is challenging.

The present study aimed to implement ELECTRE-TRI and FlowSort in SPS to understand how these methods perform in SPS problems. As SPS is an attractive field of finance and obtaining real returns in finance is possible, the results can be analyzed accordingly. SPS is an important decision process for investors to select stocks from a large pool of stocks (Hargreaves 2013). Compared with PROMETHEE methods, ELECTRE methods have been used more in SPS problems, and in some studies, the ELECTRE-TRI method has been applied. For instance, Hurson and Zopounidis (1997) applied ELECTRE-TRI and MINORA methods in an SPS problem, and Xidonas et al. (2009a) applied ELECTRE-TRI, ELECTRE III, and a nonlinear model in the SPS problem. These studies were conducted in Athens Stock Exchange. Hurson and Ricci-Xella (1998) and Hurson and Ricci-Xella (2002) applied ELECTRE-TRI and MINORA to the French stock market for SPS. Mehregan et al. (2018) applied UTADIS in SPS, and after a post optimality stage, stocks were classified into two groups. Mehregan et al. (2019) applied ELECTRE-TRI in SPS and considered four approaches in their study. In the present study, research results obtained by Mehregan et al. (2019) and 15 approaches for FlowSort were taken into account. Finally, 19 approaches were considered to classify stocks. The best-worst method (BWM) was applied to identify the criteria weights as it is compatible with the problem of this study and the number of comparisons is suitable (2n-3). The current study is performed on the Tehran Stock Exchange (TES). Established in 1967, it is the largest stock exchange in Iran with a market capitalization of 226 billion dollars.

This study presents an application of two known multi-criteria sorting methods to an SPS problem. The present study applies the FlowSort in an SPS context for the first time. This study is the first to use a hybrid approach using BWM and FlowSort in a real problem. To the best of the authors' knowledge, a comprehensive sensitivity analysis on all method parameters, as conducted in this study, has not occurred in other studies. This research also analyzes the results obtained by the ELECTRE-TRI and the FlowSort simultaneously.

Section "Background of SPS" introduces Markowitz's theory and the expanded framework. Section "Background for comparison of MCDM methods" presents a background 
for a comparison of MCDM methods. Section "Theoretical foundation" presents an overview of applied methods. Section "Research methodology" presents the methodology and study framework. Section "Results and discussion" presents the results and discussion. Section "Managerial implications" presents the managerial implications, and Section "Conclusion" concludes the study.

\section{Background of SPS}

SPS has been one of the most critical decision-making areas in modern finance since the 1950s (Mansour et al. 2019). SPS aims at assessing a combination of securities from a wide range of available alternatives. The modern portfolio theory (MPT) proposed by Markowitz (1952) transformed the field of finance. Markowitz received a nobel prize for his pioneering theoretical contributions to economics after proposing the MPT. The proposed model has two important aspects. First, any investor's preference is to maximize return. Second, having a diversified portfolio of unrelated securities can decrease risk. Markowitz proposed the model in the form of a mathematical program (Eq. (1)) (Aouni et al. 2018).

$$
\begin{aligned}
& \operatorname{Min}\left\{\sum_{i=1}^{m} \sum_{j=1}^{m} x_{i} \sigma_{i j} x_{j}\right\} \\
& \text { s.t. } \\
& \sum_{i=1}^{m} E\left(r_{i}\right) x_{i}=\rho \\
& \sum_{i=1}^{m} x_{i}=1 \\
& x_{i} \geq 0, i=1, \ldots, m
\end{aligned}
$$

In this model, $r_{i}$ is the random variable for the return to be realized on a security $i$ over a future period. $E\left(r_{i}\right)$ is the expected rate of return on stock $i ; \rho$ is the desired expected return for the portfolio; $\sigma_{i j}$ is the covariance of $r_{i}$ with $r_{j} ; x_{i}$ is the proportion of capital invested in stock $i$, and $m$ is the number of assets. According to the proposed model, investors must make a trade-off between maximizing return and minimizing risk (Rahiminezhad Galankashi et al. 2020). In addition to the Markowitz model, Sharpe (1963) and Perold (1984) also proposed index models. They introduced the concept of factors affecting stock prices for enabling investors to reduce the amount of computation. Later, Sharpe (1964) and Lintner (1965) proposed the capital asset pricing model, and Ross (1976) developed the arbitrage pricing theory. More recent studies suggested considering additional decision criteria for SPS (Mansour et al. 2019). Ehrgott et al. (2004) extended the model of Markowitz mean-variance, considering five objectives related to return and risk. A utility function of DM was defined for each objective. Huang (2008) developed a new model by giving a new definition of SPS risk and applying a hybrid intelligent algorithm to solve the model.

Remarkably, after years, MPT has remained largely intact. Although this framework has endured many criticisms, one criticism has perhaps been the most persistent. The basic model is not able to consider additional criteria. In MPT, two criteria 
include the expected value of the portfolio's return random variable (Return) and the random variable (Risk) variance, considered the main inputs. However, investors may have additional concerns (Steuer et al. 2008). As investors face different options, aspects that influence their attitudes should be considered (Atta Mills et al. 2020). Most studies on SPS focused on return and risk as to the main decision-making criteria. However, several other important criteria have been ignored (Sundar et al. 2016; Rahiminezhad Galankashi et al. 2020). Lee and Lerro (1973) attested to a growing need for including criteria beyond mean and variance. Since 1973, many criterion ideas have been introduced in the multi-criteria portfolio selection (Aouni et al. 2018). Many multi-criteria methods have been applied in SPS (Bouri et al. 2002; Dominiak 1997; Gupta et al. 2013; Jerry Ho et al. 2011; Kazemi et al. 2014; Tiryaki and Ahlatcioglu 2005; Touni et al. 2019). In this expanded framework, multi-criteria sorting methods have been applied for constructing a list of securities (Dimitras and Sagka 2012; Hurson and Zopounidis 1997; Mehregan et al. 2018; Xidonas et al. 2009b; Xidonas and Psarras 2010). As an unsupervised learning algorithm, cluster analysis (CA) is another developed approach for SPS. CA is a multivariate statistical method for categorizing stocks into homogeneous categories (Mansour et al. 2019). The current study intends to recommend stocks using multi-criteria sorting methods.

\section{Background for comparison of MCDM methods}

In previous studies, researchers attempted to compare MCDM methods. For instance, Parkan and Wu (2000) compared three procedures: OCRA, AHP, and DEA. The comparison was performed based on the size of the problem, computational ease, flexibility, and adaptability. Then, Thor et al. (2013) compared four MCDM methods (i.e., AHP, ELECTRE, SAW, and TOPSIS) from the perspective of maintenance alternative selection. Comparisons were based on consistency, problem structure, concept, core process, and the accuracy of final results. The results showed that TOPSIS exhibits the highest potential in maintenance decision analysis. For an equipment selection problem, Hodgett (2016) evaluated three MCDM methods (i.e., AHP, MARE, and ELECTRE). The results revealed that MARE is the most effective method for accurately representing the DM's preferences and comprehending the present uncertainty. To assess sustainable housing affordability, Mulliner et al. (2016) compared MCDM methods (WPM, WSM, revised AHP, AHP, TOPSIS, and COPRAS). In this study, 20 evaluation criteria and 10 alternatives were considered. Researchers concluded that ideally and where possible, more than one method should be applied to the same problem to provide a more comprehensive decision basis. Asgharizadeh et al. (2019) clustered 17 MCDM methods in two clusters using the fuzzy c-means method. This clustering was based on seven variables (i.e., simplicity in learning and developing, speed, complexity of calculations, the number of inputs, the quality of the underlying logic, the quality of ranking, and the growth rate in large problems). Ameri et al. (2018) compared four MCDM methods: SAW, TOPSIS, VIKOR, and compound factor (CF). They prioritized sub-watersheds using the percentage and intensity of changes. The results indicated that VIKOR has a higher performance than TOPSIS, SAW, and CF. Vakilipour et al. (2021) evaluated the quality of life at different spatial levels using SAW, TOPSIS, VIKOR, and ELECTRE methods. They computed 
Table 1 Summary of relevant studies on MCDM methods

\begin{tabular}{|c|c|c|}
\hline References & Applied methods & Basis of analysis \\
\hline Parkan and Wu (2000) & OCRA, AHP, and DEA & $\begin{array}{l}\text { Size of the problem, computational ease, } \\
\text { flexibility, and adaptability }\end{array}$ \\
\hline Thor et al. (2013) & AHP, ELECTRE, SAW, and TOPSIS & $\begin{array}{l}\text { Consistency, problem structure, concept, } \\
\text { core process, and the accuracy of final } \\
\text { results }\end{array}$ \\
\hline Hodgett (2016) & AHP, MARE, and ELECTRE & Final results \\
\hline Mulliner et al. (2016) & $\begin{array}{l}\text { WPM, WSM, revised AHP, AHP, TOPSIS, } \\
\text { and COPRAS }\end{array}$ & Final results \\
\hline Asgharizadeh et al. (2019) & $\begin{array}{l}\text { SAW, ELECTRE, TOPSIS, ORESTE, } \\
\text { PROMETHEE I, EVAMIX, MAUT, REGIME, } \\
\text { MAPPAC, TACTIC, VIKOR, ARGUS, COPRAS, } \\
\text { SMART, PACMAN, MOORA, and ARAS }\end{array}$ & $\begin{array}{l}\text { Simplicity in learning and developing, } \\
\text { speed, complexity of calculations, the } \\
\text { number of inputs, the quality of the } \\
\text { underlying logic, the quality of ranking, } \\
\text { and the rate of growth in large problems }\end{array}$ \\
\hline Ameri et al. (2018) & $\begin{array}{l}\text { SAW, TOPSIS, VIKOR, and compound } \\
\text { factor (CF) }\end{array}$ & Percentages of change \\
\hline Vakilipour et al. (2021) & SAW, TOPSIS, VIKOR, and ELECTRE & Correlation and stability \\
\hline
\end{tabular}

the correlation and the stability of the methods to compare the methods. Table 1 presents a summary of relevant studies on MCDM methods.

\section{Theoretical foundation}

\section{BWM}

The problem of deriving priorities from pairwise comparisons is the core of MCDM problems (Zhang et al. 2021). The BWM (Rezaei 2015) is an MCDM method that applies two vectors of pairwise comparisons to define the weights of criteria. The BWM is similar to the AHP, and both are based on pairwise comparisons. The AHP is a widely used method in MCDM, and its root dates back to 1972 (Yu et al. 2021). BWM requires fewer pairwise comparisons than AHP, which is the main advantage of BWM. In BWM, DM determines the best and worst criteria and compares the best criterion over all the other criteria and then all the other criteria to the worst criterion. This structure helps the DM to have a clear understanding of evaluation and leads to more reliable comparisons. BWM is the most data- and time-efficient model, which can check the consistency of comparisons (Rezaei 2020). The steps of BWM are as follows:

Step 1. Determine a set of decision criteria $\left\{g_{1}, \ldots, g_{j}, \ldots, g_{n}\right\}$. The recommended number of criteria should not exceed nine. In general, the DM cannot process information to make comparisons for many criteria (La Fata et al. 2021).

Step 2. Determine the best (e.g., most desirable, most important) and the worst (e.g., least desirable, least important) criteria.

Step 3. Determine the preference of the best criterion over all the other criteria using a number between 1 and 9 . The best-to-other vector can be shown as $A_{B}=\left(a_{B 1}, \ldots, a_{B j}, \ldots\right.$, $\left.a_{B n}\right)$ where $a_{B j}$ indicates the preference of criterion ${ }_{B}$ over criterion $j(j=1, \ldots, n)$. 
Step 4. Determine the preference of all criteria over the worst criterion using a number between 1 and 9. The others-to-worst vector can be shown as $A_{W}=\left(a_{1 W}, \ldots, a_{j W}, \ldots, a_{n W}\right)^{T}$, where $a_{j W}$ indicates the preference of criterion $j$ over the worst criterion $W$.

Step 5. Find the optimal weights $\left(w_{1}^{*}, \ldots, w_{j}^{*}, \ldots, w_{n}^{*}\right)$ and $\varepsilon^{*}$ using Eq. (2).

$\min \varepsilon$

s.t.

$\left|\frac{w_{B}}{w_{j}}-a_{B j}\right| \leq \varepsilon, \quad$ for all $j$

$\left|\frac{w_{j}}{w_{W}}-a_{j W}\right| \leq \varepsilon, \quad$ for all $j$

$\sum_{j} w_{j}=1$

$w_{j} \geq 0, \quad$ for all $j$

Pairwise comparisons come from the DM's subjective judgments, where inconsistencies exist naturally (Wang et al. 2021). BWM can calculate the consistency between pairwise comparisons. After solving the above model, the reliability of the weights can be checked using a consistency ratio $(C R)$. Considering the consistency index $(C I)$ (Table 2), the $C R$ is calculated as in Eq. (3).

$$
C R=\frac{\varepsilon^{*}}{C I}
$$

\section{Multi-criteria Sorting Methods}

In the current study, the multi-criteria sorting approach creates a stock portfolio. The multi-criteria sorting approach is well adapted to the nature of the SPS problem as conflicting multi-criteria in this approach can be considered. In multi-criteria sorting methods, the order of groups is always specified. That is, the first group always contains the best alternatives. In the SPS problem, we attempt to find the best stocks and form a stock portfolio accordingly. Thus, the multi-criteria sorting approach can provide an appropriate structure for solving SPS problems. In this section, the steps of ELECTRE-TRI and FlowSort are explained. Those methods are also known as ordinal sorting methods.

\section{ELECTRE-TRI}

ELECTRE-TRI is an MCDM method belonging to ELECTRE family methods and one of the most well-known ordinal sorting methods. This method involves assessing each alternative on several quantitative and/or qualitative criteria (Micale et al. 2019a). ELECTRE-TRI assigns alternatives to predefined ordered groups by comparing the alternatives with the profiles defining the limits of the groups (or categories). $F$

Table 2 Consistency Index

\begin{tabular}{llllllllll}
\hline$a_{B W}$ & $\mathbf{1}$ & $\mathbf{2}$ & $\mathbf{3}$ & $\mathbf{4}$ & $\mathbf{5}$ & $\mathbf{6}$ & $\mathbf{7}$ & $\mathbf{8}$ & $\mathbf{9}$ \\
\hline$C l(\max \varepsilon)$ & 0.00 & 0.44 & 1.00 & 1.63 & 2.30 & 3.00 & 3.73 & 4.47 & 5.23 \\
\hline
\end{tabular}


denotes the set of indices of the criteria $g_{1}, \ldots, g_{j}, \ldots, g_{n}(F=\{1,2, \ldots, n\})$, and $B$ is the set of indices of the profiles defining $p+1$ groups $(B=\{1,2, \ldots, p\}) . b_{h}$ is the upper profile of group $C_{h}$ and the lower profile of group $C_{h+1}, h=1,2, \ldots, p$. The categories to which the actions must be assigned are completely ordered such that the limiting profiles $b_{h}$ must fulfill the dominance-base separability condition (Fernández et al. 2017). ELECTRE-TRI uses outranking relations to validate or invalidate assertation $a S b_{h}$ (and $b_{h} S a$ ), which means that " $a$ is at least as good as $b_{h}$." Indifference, preference, and veto thresholds (i.e., $q_{j}\left(b_{h}\right), p_{j}\left(b_{h}\right)$, and $\left.v_{j}\left(b_{h}\right)\right)$ constitute the intra-criteria preferential information.

The indifference threshold is the biggest difference between the performance of the alternatives and profiles on the criterion; thus, the DM considers them indifferent. The preference threshold is the greatest difference between the performance of the alternatives and profiles such that one is preferable to the other on the considered criterion (Ishizaka and Nemery 2013). The veto threshold indicates situations when the performance difference between the alternatives and profiles on a specific criterion requires the DM to negate any outranking relationship indicated by other criteria (Nowak 2004). The steps of ELECTRE-TRI are below.

Step 1. Compute partial concordance indices $\left(c_{j}\left(a, b_{h}\right) \forall j \in \mathrm{F}\right)$. The concordance index measures the strength of the hypothesis that alternative $a$ is at least as good as profile $b_{h}$ (Mary and Suganya 2016). The partial concordance index can be calculated for each criterion by Eq. (4).

$$
c_{j}\left(a, b_{h}\right)= \begin{cases}0 & \text { if } g_{j}\left(b_{h}\right)-g_{j}(a) \geq p_{j}\left(b_{h}\right) \\ 1 & \text { if } g_{j}\left(b_{h}\right)-g_{j}(a) \leq q_{j}\left(b_{h}\right) \\ \frac{p_{j}\left(b_{h}\right)+g_{j}(a)-g_{j}\left(b_{h}\right)}{p_{j}\left(b_{h}\right)-q_{j}\left(b_{h}\right)} & \text { otherwise }\end{cases}
$$

Step 2. Compute the comprehensive concordance index $\left(c\left(a, b_{h}\right)\right)$.

After calculating the partial concordance index for all criteria, the comprehensive concordance index can be calculated using Eq. (5).

$$
c\left(a, b_{h}\right)=\frac{\sum_{j \in F} w_{j} \cdot c_{j}\left(a, b_{h}\right)}{\sum_{j \in F} w_{j}}
$$

Step 3. Compute discordance indices $\left(d_{j}\left(a, b_{h}\right) \forall j \in \mathrm{F}\right)$.

The discordance index specifies the strength of evidence against the hypothesis that alternative $a$ is at least as good as profile $b_{h}$ (Mary and Suganya 2016). The discordance index can be calculated using Eq. (6).

$$
d_{j}\left(a, b_{h}\right)= \begin{cases}0 & \text { if } g_{j}\left(b_{h}\right)-g_{j}(a) \leq p_{j}\left(b_{h}\right) \\ 1 & \text { if } g_{j}\left(b_{h}\right)-g_{j}(a)>v_{j}\left(b_{h}\right) \\ \frac{g_{j}\left(b_{h}\right)-g_{j}(a)-p_{j}\left(b_{h}\right)}{v_{j}\left(b_{h}\right)-p_{j}\left(b_{h}\right)} & \text { otherwise }\end{cases}
$$

Step 4. Compute the credibility index of the outranking relation $\left(\sigma\left(a, b_{h}\right)\right)$.

The degree of credibility $\left(\sigma\left(a, b_{h}\right) \in[0,1]\right)$ is an index that shows the credibility of assertation $a S b_{h}$ (and $b_{h} S a$ ) in ELECTRE-TRI. Assertation $a S b_{h}$ (and $b_{h} S a$ ) is valid if $\sigma\left(a, b_{h}\right) \geq \lambda\left(\sigma\left(b_{h} a\right) \geq \lambda\right) . \lambda$ is a cutting level such that $\lambda \in[0.5,1] . \sigma\left(a, b_{h}\right)$ can be obtained by Eq. (7) $\left(\sigma\left(b_{h}, a\right)\right.$ can be computed analogously): 


$$
\sigma\left(a, b_{h}\right)=\left\{c\left(a, b_{h}\right) \cdot \prod_{j \in \bar{F}} \frac{1-d_{j}\left(a, b_{h}\right)}{1-c\left(a, b_{h}\right)}\right.
$$

where

$$
\bar{F}=\left\{j \in F: d_{j}\left(a, b_{h}\right)>c\left(a, b_{h}\right)\right.
$$

The preference situation between $a$ and $b_{h}$ can be determined by the value of $\sigma\left(a, b_{h}\right)$, $\sigma\left(b_{h} a\right)$ and $\lambda$ :

$$
\begin{aligned}
& \sigma\left(a, b_{h}\right) \geq \lambda \text { and } \sigma\left(b_{h}, a\right) \geq \lambda \Rightarrow a S b_{h} \text { and } b_{h} S a \Rightarrow a I b_{h}\left(a \text { is indifferent to } b_{h}\right) . \\
& \sigma\left(a, b_{h}\right) \geq \lambda \text { and } \sigma\left(b_{h}, a\right)<\lambda \Rightarrow a S b_{h} \text { and not } b_{h} S a \Rightarrow a \succ b_{h}\left(a \text { is preferred to } b_{h}\right) . \\
& \sigma\left(a, b_{h}\right)<\lambda \text { and } \sigma\left(b_{h}, a\right) \geq \lambda \Rightarrow \text { not aSb } b_{h} \text { and } b_{h} S a \Rightarrow b_{h} \succ a\left(b_{h} \text { is preferred to } a\right) . \\
& \sigma\left(a, b_{h}\right)<\lambda \text { and } \sigma\left(b_{h}, a\right)<\lambda \Rightarrow \text { not aSb } b_{h} \text { and not } b_{h} S a \Rightarrow b_{h} \operatorname{Ra}\left(a \text { is incomparable to } b_{h}\right) .
\end{aligned}
$$

Increasing the value of $\lambda$ makes it difficult for an alternative to outrank a profile and vice versa. Correlatively, the number of incomparability relations has increased (Micale et al. 2019b)

Step 5. Assign alternatives to categories.

Two assignment procedures exist:

Pessimistic procedure: Compare $a$ successively to $b_{t}$, for $t=p, p-1, \ldots, 1 ; b_{h}$ being the first profile such that $a \mathrm{Sb}_{h}$; assign $a$ to category $\mathrm{C}_{h+1}$.

Optimistic procedure: Compare $a$ successively to $b_{t}$, for $t=1,2, \ldots, p ; b_{h}$ being the first profile such that $b_{h} \succ a$; assign $a$ to category $\mathrm{C}_{h}$.

The pessimistic approach can be applied in situations requiring caution or with limited resources. The optimistic approach can be applied to encourage alternatives that have attractive or exceptional qualities (Ramezanian 2019). Notably, if an alternative is incomparable to one or more profiles, a divergence exists in the outcomes obtained by the two approaches. In this situation, the pessimistic approach assigns the alternative to a group lower than the optimistic approach (Mendas et al. 2020).

Unlike clustering methods, in multi-criteria sorting methods, the order of groups is always specified. The first group always contains the best alternatives, whereas the last group always contains the worst ones. Therefore, in multi-criteria sorting methods, no further step is needed for ranking groups. Additional details on ELECTRE-TRI can be found in Mousseau et al. (2001) and Rogers et al. (2013).

\section{FlowSort}

FlowSort (Nemery and Lamboray 2008) is an extension of the PROMETHEE method for assigning alternatives to predefined ordered categories $\left(\mathrm{C}_{1}, \mathrm{C}_{2}, \ldots, \mathrm{C}_{p}\right)$. FlowSort needs input data, including criteria weights, alternatives' performance, reference profiles, and thresholds. In this method, categories are definable by two limiting profiles or one central profile. In this study, two limiting profiles are considered for defining categories. 
That is, a category is defined by the upper and lower profiles and $b_{1} \succ b_{2} \succ \ldots \succ b_{p+1}$ because the categories are completely ordered. The steps of FlowSort are as follows:

Step 1. Compute the preference degree.

$\mathrm{R}_{i}$ denotes the set of reference profiles and is an alternative to be classified as $\left\{b_{1}, \ldots\right.$, $\left.b_{p+1}\right\} \cup\left\{a_{i}\right\}, i=1, \ldots, m . b_{1}$ is the best, whereas $b_{p+1}$ is the worst profile. The preference degree $p_{j}(x, y)(\forall j \in\{1, \ldots, n\})$ can be computed for any pair of $(x, y) \in \mathrm{R}_{i} \cdot p_{j}(x, y)$ calculates the preference strength of $x$ over $y$ in criterion $j$ by considering the deviation between $x$ and $y$ and the DM preferences. The amount of deviation between $x$ and $y$ can be calculated using Eq. (9).

$$
d_{j}(x, y)=g_{j}(x)-g_{j}(y)
$$

The preference degree for benefit criteria can be obtained by Eq. (10), and that for cost criteria can be obtained by Eq. (11). The value of $P_{j}(x, y)$ ranges from 0 to 1 .

$$
\begin{aligned}
& P_{j}(x, y)=F_{j}\left[d_{j}(x, y)\right] \\
& P_{j}(x, y)=F_{j}\left[-d_{j}(x, y)\right]
\end{aligned}
$$

DM should select the desired function shape. "Appendix 1" shows five types of preference functions.

Step 2. Compute the global preference degree.

The global preference degree of each pair of alternatives can be computed as in Eq. (12):

$$
\pi(x, y)=\sum_{j=1}^{n} p_{j}(x, y) \cdot w_{j}
$$

Step 3. Compute the leaving (positive), entering (negative), and net flows.

Leaving, entering, and net flows for the set of $R_{i}$ can be computed as in Eqs. (13)-(15) $\left(x \in \mathrm{R}_{i}\right)$.

$$
\begin{aligned}
& \Phi_{R_{i}}^{+}(x)=\frac{1}{\left|R_{i}\right|-1} \sum_{y \in R_{i}} \pi(x, y) \\
& \Phi_{R_{i}}^{-}(x)=\frac{1}{\left|R_{i}\right|-1} \sum_{y \in R_{i}} \pi(y, x) \\
& \Phi_{R_{i}}(x)=\Phi_{R_{i}}^{+}(x)-\Phi_{R_{i}}^{-}(x)
\end{aligned}
$$

where $\left|R_{i}\right|$ is the number of elements belonging to set $R_{i}$.

Step 4. Assign alternatives to categories.

Finally, the assignment of alternative $a$ to category $\mathrm{C}_{\mathrm{h}}$ can be performed based on net flows as in Eq. (16).

$$
C_{\Phi}\left(a_{i}\right)=C_{h} \quad \text { if } \quad \Phi_{R_{i}}\left(b_{h}\right) \geq \Phi_{R_{i}}\left(a_{i}\right)>\Phi_{R_{i}}\left(b_{h+1}\right)
$$


Similar assignment rules are based on $\Phi_{R_{i}}^{+}\left(a_{i}\right)$ and $\Phi_{R_{i}}^{-}\left(a_{i}\right)$ to obtain $\mathrm{C}^{+}\left(a_{i}\right)$ and $\mathrm{C}^{-}\left(a_{i}\right)$ (Eqs. (17)-(18)).

$$
\begin{aligned}
& C_{\Phi^{+}}\left(a_{i}\right)=C_{h} \quad \text { if } \quad \Phi_{R_{i}}^{+}\left(b_{h}\right) \geq \Phi_{R_{i}}^{+}\left(a_{i}\right)>\Phi_{R_{i}}^{+}\left(b_{h+1}\right) \\
& C_{\Phi^{-}}\left(a_{i}\right)=C_{h} \quad \text { if } \quad \Phi_{R_{i}}^{-}\left(b_{h}\right)<\Phi_{R_{i}}^{-}\left(a_{i}\right) \leq \Phi_{R_{i}}^{-}\left(b_{h+1}\right)
\end{aligned}
$$

Additional details on FlowSort can be found in Nemery and Lamboray (2008), Janssen and Nemery (2013), and Campos et al. (2015).

\section{CA}

\section{K-means clustering}

The K-means clustering is a popular algorithm, which was described by MacQueen (1967). In this algorithm, the number of clusters $k$ should be determined before clustering. K-means allocates the alternative to the nearest cluster. An error function exits, which should be calculated after each iteration. This process will be stopped when the error function or the membership of the clusters does not change. Two following main steps can describe K-means.

Step 1. The K-means randomly allocates the alternatives into $k$ clusters.

Step 2. The distance between each alternative and cluster should be calculated. Alternatives should be allocated to the nearest cluster. This step is the iteration phase.

The error function can be computed as in Eq. (19).

$$
\text { Error function }=\sum_{i=1}^{k} \sum_{x \in C_{i}} d\left(x, \mu\left(C_{i}\right)\right)
$$

where $\mu\left(C_{i}\right)$ is the center of cluster $i . k$ is the number of clusters, and $x$ is an alternative that belongs to cluster $i . d\left(x, \mu\left(C_{i}\right)\right)$ denotes the distance between $x$ and $\mu\left(C_{i}\right)$. The Euclidean distance can be considered for calculating the distance (Gan et al. 2007).

\section{Cluster validation}

Cluster validation is a process of evaluating how well a partition fits the structure underlying the data. Generally, the number of clusters is determined by running the clustering algorithm several times with different numbers of clusters. The partitions that best fit the data should be selected (Arbelaitz et al. 2013).

Silhouette coefficient The silhouette coefficient (SC) (Kaufman and Rousseeuw 2009) is a useful measure for indicating the amount of the clustering structure for a clustering method. This coefficient can be used to determine the optimum number of groups. The silhouette value for $i$ th alternative $\left(s_{i}\right)$ can be calculated by Eq. (20).

$$
s_{i}=\frac{b_{i}-a_{i}}{\max \left(a_{i}, b_{i}\right)}
$$

where $a_{i}$ denotes the average distance between $i$ th and other alternatives in the same cluster. $b_{i}$ is the minimum average distance between $i$ th and alternatives in a different 
cluster, which is minimized over clusters. $\bar{s}(k)$ is the average of $s_{i}$ for all alternatives and regarded as the average silhouette width. The SC can be computed by Eq. (21).

$$
S C=\max _{k} \bar{s}(k)
$$

"Appendix 2" shows the proposed interpretation for SC. The silhouette test evaluates the SC of clustering results iteratively with different cluster numbers. The silhouette test is easy because the principle is to select the optimal number of clusters based on the highest score (Li et al. 2021).

Davies-Bouldin index The Davies-Bouldin index (Davies and Bouldin 1979) is defined by Eq. (22).

$$
\mathrm{DB}=\frac{1}{k} \sum_{i=1}^{k} \max _{i \neq j}\left\{D_{i, j}\right\}
$$

In the above equation, $D_{i, j}$ is the within-to-between cluster distance ratio for the $i$ th and $j$ th clusters. $D_{i, j}$ can be computed as in Eq. (23).

$$
D_{i, j}=\frac{\left(\bar{d}_{i}+\bar{d}_{j}\right)}{d_{i, j}}
$$

where $\bar{d}_{i}$ and $\bar{d}_{j}$ denote the average distance between each alternative in the $i$ th cluster and the center of the $i$ th cluster and between each alternative in the $j$ th cluster and the center of the $j$ th cluster, respectively. $d_{i, j}$ denotes the Euclidean distance between the center of the $i$ th and $j$ th clusters. The optimal clustering has the smallest Davies-Bouldin index value.

The difference between multi-criteria sorting and clustering methods is that the former use predefined ordered groups, whereas the latter identify similarities between alternatives. Unlike clustering methods, in multi-criteria sorting methods, the ranking of groups is always specified. Multi-criteria sorting methods seem to have stronger and more diverse theoretical foundations, such as preference modeling, with different features than clustering methods.

\section{Research methodology}

This section presents a step-by-step research methodology. Figure 1 depicts the research framework. In this study, we followed the steps proposed by Mehregan et al. (2019) to provide a fair comparison of the results for different parameters of the methods.

Step 1. The first step is collecting previous studies and extracting the most frequent factors through the literature review. In this step, the frequency of indicators from 63 articles was considered a basis for the initial selection of indicators. Then, the indicators that were used in more than 15 articles were identified. There were nine widely used indicators. Twelve financial experts, including four stock portfolio managers, four investment company managers, and four finance professors, checked the factors. Each expert then filled out a five-point Likert scale questionnaire including nine factors 


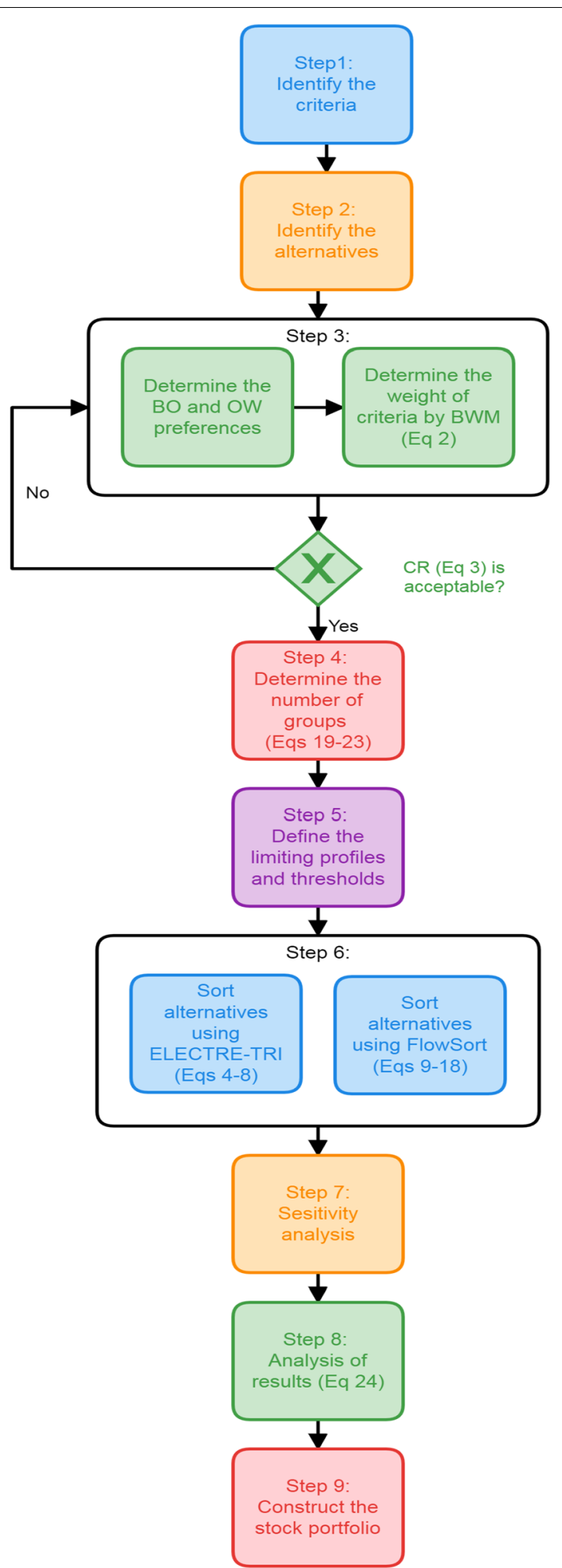

Fig. 1 Flow diagram of the research methodology 
during a session that lasted an average of one hour. The experts were asked to indicate any significant factors not included in the questionnaire. According to the average scores of each factor, eight factors were chosen. The investor confirmed the process of determining factors and the obtained factors for SPS. The identified indicators are briefly explained as follows:

Return: An investment's yield is often expressed as a percentage of the amount invested (Rezaeian and Akbari 2015).

Earnings per share (EPS): EPS indicates the amount of money a company can make from each stock share (Amin and Hajjami 2021).

Price/earnings ratio (P/E): The main concept behind the $\mathrm{P} / \mathrm{E}$ is the market's willingness to pay for the firm's earnings (Yalcin et al. 2012).

Beta (systematic risk): The dependency of a stock's return on the market is measured by beta (Abdelaziz et al. 2007).

Return on assets (ROA): The percentage of a company's ability to generate a return from its assets (Amin and Hajjami 2021).

Return on equity (ROE): The percentage of profit earned on common stockholders' investment in the companies (Yalcin et al. 2012).

Price to book value $(\mathbf{P} / \mathbf{B V})$ : The $\mathrm{P} / \mathrm{BV}$ estimates the stock's market value to its book value per share (Kadim et al. 2020).

Net profit margin: The net profit margin is a percentage that indicates how much of a company's revenues are kept as net income (Rist and Pizzica 2015).

Step 2. Fifty companies were selected according to the list of 50 most active companies published by the Securities and Exchange Organization per season. Companies that had the most repetitions in this list during the 12 seasons were selected.

Step 3. The weight of factors was obtained through BWM.

Step 4. The final number of groups was obtained by researching three aspects, namely, clustering quality measures (SC and Davies-Bouldin index), previous studies, and investor preference. Clustering techniques group alternatives by similarity. Although applying clustering techniques provides a very different result without ordering the groups, this step was done as an exploratory analysis to differentiate some alternatives. Clustering quality measures represent how well each alternative has been classified, and they were used to determine the number of groups.

Step 5. The researcher and investor agreement defined profiles and parameters for ELECTRE-TRI and FlowSort. The analyst should explain the meaning of parameters to DM to obtain the proper values (Brito et al. 2010). Therefore, the concept of these parameters and limiting profiles was explained to the investor. The investor was then asked to determine the values of parameters and limiting profiles. In determining the values of the parameters and profiles, the researcher provided feedback to the investor. In some cases, the values were modified with the acceptance of the investor.

Step 6. ELECTRE-TRI and FlowSort were applied to sort stocks. In the present study, 15 approaches for FlowSort and four approaches for ELECTRE-TRI were considered. In other words, at the end of the study, we had 19 assessments over different approaches. 
Step 7. A comprehensive sensitivity analysis was performed based on factor weights, first profile, preference thresholds, indifference thresholds, and cutting level. Considering this sensitivity analysis can decrease the effect of different definitions of parameters' values by different DMs.

Step 8 . The results were analyzed by considering the real return in the next period (year). Analysis was performed based on the value from Eq. (24). A larger value of $F$ shows a better result.

$$
F=\frac{\sum_{i=1}^{m} x_{i} \cdot y_{i}}{m} \cdot 100
$$

where $x_{i}$ and $y_{i}$ can be calculated using Eqs. (25) and (26), and $n$ is the number of stocks in the portfolio.

$$
\begin{aligned}
& x_{i}= \begin{cases}1 & \text { If stock ith is in portfolio } \\
0 & \text { Otherwise }\end{cases} \\
& y_{i}= \begin{cases}1 & \text { If return of stock ith is more than average return of all stocks } \\
0 & \text { Otherwise }\end{cases}
\end{aligned}
$$

Step 9. The stock portfolio was constructed based on the best result.

This research performed computations by ELECTRE-TRI 2.0a software for ELECTRETRI, Smart-PickerPro 4.3 for FlowSort, LINGO 11.0 for BWM, and MATLAB 2016 for $\mathrm{K}$-means clustering. This research was conducted in the National Investment Company of Iran, and stocks were selected from the TSE market. Table 3 shows the average historical data of stocks from 2011 to 2014, which were obtained from Rahavard Novin software. Rahavard Novin is a software that collects financial data of stocks from TSE. Table 4 shows which industry group the stock belongs to.

\section{Results and discussion}

As ELECTRE-TRI and FlowSort need the weight of criteria, the BWM was employed to determine the weight of eight criteria. Table 5 presents the result of the BWM.

SC and Davies-Bouldin indices were computed by MATLAB 2016 using the K-means clustering method to detect the optimal number of groups. The best value for the SC was 0.675 for the three groups. Similarly, the best value for the Davies-Bouldin index was 0.37 for the three groups.

A review of similar studies also indicated that, in many cases, researchers considered three groups for classifying stocks. For example, Hurson and Zopounidis (1997), Zopounidis et al. (1999), Hurson and Ricci-Xella (2002), Doumpos and Zopounidis (2002), Xidonas and Psarras (2010), and Zitouni (2014) considered three groups for classification in their studies. In addition, the investor expressed that the number of groups should be three in this study. Three groups were considered based on the above validation criteria, previous studies, and investor preferences. Multi-criteria sorting methods classify alternatives into predefined groups, and these groups are in order. The first group 
Table 3 Decision matrix

\begin{tabular}{|c|c|c|c|c|c|c|c|c|c|}
\hline Code & Alternative & Return & Beta & $\begin{array}{l}\text { Net Profit } \\
\text { Margin }\end{array}$ & ROA & ROE & EPS & $\mathrm{P} / \mathrm{E}$ & P/BV \\
\hline $\mathrm{A} 1$ & Azarab & 86.692 & 1.146 & 10.327 & 4.94 & 22.855 & 402 & 7.169 & 2.183 \\
\hline $\mathrm{A} 2$ & $\begin{array}{l}\text { Mobile Telecom- } \\
\text { munication Com- } \\
\text { pany of Iran }\end{array}$ & 23.666 & 0.322 & 31.513 & 21.389 & 29.745 & 9331.333 & 6.701 & 1.905 \\
\hline A3 & $\begin{array}{l}\text { Electric Khodro } \\
\text { Shargh }\end{array}$ & 24.695 & 1.794 & 2.418 & 2.644 & 9.642 & 127.333 & 16.885 & 1.007 \\
\hline A4 & Iran Transfo & 24.145 & 1.489 & 30.193 & 6.101 & 21.223 & 469.667 & 11.951 & 1.742 \\
\hline A5 & Iran Khodro & 0.279 & 1.42 & -1.236 & -0.081 & -39.005 & -58.333 & 100 & 3.051 \\
\hline A6 & Iran Yasa & 103.495 & 1.379 & 12.536 & 14.722 & 59.18 & 2603.667 & 7.738 & 2.981 \\
\hline A7 & Bama & 35.747 & 1.005 & 52.491 & 34.533 & 44.535 & 1565.333 & 7.145 & 3.172 \\
\hline A8 & Behceram & 121.102 & 1.103 & 2.073 & 0.758 & -28.316 & 58.667 & 69.733 & 20.786 \\
\hline A9 & Pars Khodro & 31.643 & 1.146 & -10.159 & -6.553 & -47.223 & -505.333 & 250 & 0.828 \\
\hline $\mathrm{A} 10$ & $\begin{array}{l}\text { Kharg Petrochem- } \\
\text { ical Company }\end{array}$ & 67.379 & 1.276 & 72.002 & 61.141 & 85.927 & 7527.333 & 4.853 & 4.228 \\
\hline A11 & $\begin{array}{l}\text { Shazand } \\
\text { Petrochemical } \\
\text { Company }\end{array}$ & 204.761 & 1.302 & 17.371 & 24.637 & 59.911 & 3313.333 & 8.091 & 3.121 \\
\hline $\mathrm{A} 12$ & $\begin{array}{l}\text { Shiraz Petrochem- } \\
\text { ical Company }\end{array}$ & 97.489 & 0.593 & 45.938 & 14.533 & 45.104 & 1171.667 & 8.333 & 3.108 \\
\hline A13 & $\begin{array}{l}\text { Fanavaran } \\
\text { Petrochemical } \\
\text { Company }\end{array}$ & 100.181 & 1.391 & 64.639 & 43.411 & 68.788 & 4802.333 & 6.142 & 4.075 \\
\hline A14 & Techinco & 46.36 & 0.939 & 14.166 & 11.607 & 26.443 & 743.667 & 14.388 & 1.911 \\
\hline A15 & $\begin{array}{l}\text { Behshahr Indus- } \\
\text { trial Development } \\
\text { Corp }\end{array}$ & 46.993 & 1.159 & 96.066 & 14.912 & 19.765 & 374 & 9.979 & 1.765 \\
\hline A16 & $\begin{array}{l}\text { Chadormalu } \\
\text { Industrial Com- } \\
\text { pany }\end{array}$ & 54.133 & 1.186 & 62.478 & 41.887 & 56.698 & 1506.667 & 5.569 & 3.994 \\
\hline A17 & North Drilling & 82.361 & 1.023 & 28.614 & 14.808 & 34.276 & 664 & 11.682 & 2.669 \\
\hline A18 & $\begin{array}{l}\text { Informatics Ser- } \\
\text { vices Corporation }\end{array}$ & 61.004 & 0.471 & 144.01 & 29.242 & 50.169 & 3060.333 & 9.156 & 7.513 \\
\hline A19 & $\begin{array}{l}\text { Jaber Ebne } \\
\text { Hayyan Pharmacy }\end{array}$ & 49.54 & 1.967 & 29.94 & 18.873 & 36.125 & 1005 & 10.14 & 2.547 \\
\hline A20 & $\begin{array}{l}\text { RAZAK Pharma- } \\
\text { ceutical Company }\end{array}$ & 115.57 & 0.964 & 31.935 & 23.115 & 60.48 & 2673.667 & 8.684 & 3.436 \\
\hline A21 & Rayan Saipa & -9.145 & 1.141 & 37.453 & 4.916 & 25.06 & 628.333 & 2.726 & 1.694 \\
\hline A22 & Zamyad & -4.476 & 1.953 & -1.696 & -1.009 & -4.421 & -46 & 130 & 0.773 \\
\hline A23 & Saipa & -2.406 & 0.955 & -9.333 & -2.995 & -36.529 & -209.667 & 200 & 2.246 \\
\hline A24 & Saipa Azin & 36.293 & 1.944 & -0.547 & -0.863 & -10.613 & -72 & 105 & 1.771 \\
\hline A25 & Tehran Cement & 62.824 & 0.749 & 39.808 & 7.556 & 27.533 & 653.333 & 8.608 & 1.929 \\
\hline A26 & Khazar Cement & 129.896 & 1.148 & 17.002 & 11.337 & 29.042 & 569.333 & 11.715 & 1.78 \\
\hline A27 & $\begin{array}{l}\text { Shahroud } \\
\text { Cement }\end{array}$ & 78.941 & 1.499 & 29.087 & 17.412 & 36.373 & 755 & 8.886 & 1.81 \\
\hline A28 & Gharb Cement & 148.506 & 0.617 & 32.868 & 24.777 & 45.046 & 1088.333 & 7.491 & 2.203 \\
\hline A29 & $\begin{array}{l}\text { Shahid Ghandi } \\
\text { Corporation } \\
\text { Complex }\end{array}$ & 11.437 & 0.95 & 3.559 & 2.428 & 11.377 & 188 & 10.856 & 1.306 \\
\hline A30 & $\begin{array}{l}\text { Kermanshah } \\
\text { Petrochemical } \\
\text { Industries Com- } \\
\text { pany }\end{array}$ & 105.115 & 0.1 & 64.46 & 27.252 & 58.391 & 1484 & 6.147 & 3.021 \\
\hline A31 & $\begin{array}{l}\text { Iran Refractories } \\
\text { Company }\end{array}$ & 263.307 & 2.563 & 24.245 & 25.116 & 57.525 & 2080.667 & 9.479 & 2.521 \\
\hline
\end{tabular}


Table 3 (continued)

\begin{tabular}{|c|c|c|c|c|c|c|c|c|c|}
\hline Code & Alternative & Return & Beta & $\begin{array}{l}\text { Net Profit } \\
\text { Margin }\end{array}$ & ROA & ROE & EPS & $P / E$ & P/BV \\
\hline A32 & $\begin{array}{l}\text { Faravari Mavad } \\
\text { Madani Iran }\end{array}$ & -1.221 & 0.739 & 21.956 & 26.824 & 38.109 & 831.333 & 5.797 & 2.823 \\
\hline A33 & $\begin{array}{l}\text { Khouzestan Steel } \\
\text { Company }\end{array}$ & 139.535 & 0.739 & 26.339 & 31.301 & 62.479 & 3465.667 & 2.71 & 4.585 \\
\hline A34 & $\begin{array}{l}\text { Mobarakeh Steel } \\
\text { Company }\end{array}$ & 50.781 & 1.223 & 27.082 & 16.003 & 34.194 & 669.667 & 6.455 & 1.936 \\
\hline A35 & $\begin{array}{l}\text { Khorasan Steel } \\
\text { Company }\end{array}$ & 75.047 & 0.463 & 28.002 & 24.719 & 36.402 & 737.667 & 13.066 & 4.583 \\
\hline A36 & Calcimine & 32.199 & 1.017 & 49.163 & 32.073 & 41.901 & 1034.333 & 4.15 & 2.015 \\
\hline A37 & $\begin{array}{l}\text { Piazar Agro } \\
\text { industry }\end{array}$ & 67.954 & 0.913 & 12.533 & 12.901 & 23.099 & 404 & 9.757 & 2.814 \\
\hline A38 & Chemi Darou & 50.416 & 3.421 & 19.395 & 13.415 & 31.608 & 621.667 & 13.388 & 2.398 \\
\hline A39 & Bahman Group & 12.917 & 0.881 & 43.592 & 10.996 & 19.705 & 503.667 & 4.888 & 0.843 \\
\hline A40 & MAPNA Group & 67.118 & 1.652 & 26.533 & 3.878 & 14.733 & 545.333 & 15.937 & 1.758 \\
\hline A41 & $\begin{array}{l}\text { Golgohar Mining } \\
\text { and Industrial } \\
\text { Company }\end{array}$ & 79.686 & 1.124 & 61.344 & 36.966 & 54.492 & 1554.667 & 6.645 & 3.617 \\
\hline A42 & $\begin{array}{l}\text { Sahand Rubber } \\
\text { Industries Com- } \\
\text { pany }\end{array}$ & 171.557 & 1.419 & 49.806 & 25.332 & 38.578 & 1207.667 & 7.635 & 1.895 \\
\hline A43 & $\begin{array}{l}\text { Telecommunica- } \\
\text { tion Company } \\
\text { of Iran }\end{array}$ & 9.669 & 0.762 & 103.157 & 13.723 & 18.348 & 436.667 & 7.754 & 2.494 \\
\hline A44 & $\begin{array}{l}\text { Shahid Bahonar } \\
\text { Copper Industries } \\
\text { Company }\end{array}$ & 62.877 & 1.628 & 2.492 & 3.057 & 16.364 & 247.333 & 13.35 & 1.267 \\
\hline A45 & Bafgh Mining & 150.822 & 0.788 & 37.259 & 31.046 & 36.09 & 2201.667 & 12.932 & 4.325 \\
\hline A46 & $\begin{array}{l}\text { Iran Zinc Mines } \\
\text { Development }\end{array}$ & 23.018 & 0.87 & 101.85 & 23.686 & 27.024 & 570 & 4.323 & 1.715 \\
\hline A47 & $\begin{array}{l}\text { National Iranian } \\
\text { Lead \& Zinc } \\
\text { Company }\end{array}$ & 1.738 & 1.107 & 9.433 & 9.698 & 15.379 & 160 & 13.85 & 1.649 \\
\hline A48 & $\begin{array}{l}\text { National Iranian } \\
\text { Copper Industry } \\
\text { Company }\end{array}$ & 18.465 & 0.64 & 42.077 & 25.043 & 37.398 & 879.667 & 3.623 & 1.415 \\
\hline A49 & Mehr Cam Pars & 31.448 & 1.6 & -2.41 & -2.643 & -16.397 & -114.333 & 180 & 1.554 \\
\hline A50 & $\begin{array}{l}\text { Behran Oil Com- } \\
\text { pany }\end{array}$ & 90.647 & 1.31 & 20.255 & 20.052 & 68.113 & 3219.333 & 13.216 & 5.363 \\
\hline
\end{tabular}

contains the best alternatives, whereas the last group contains the worst ones. There are three groups of stocks in this study. The first group includes the best stocks, the third group includes the worst stocks, and the second group includes the mid-level stocks. As the best stocks are in the first group, this group can be considered a stock portfolio. The second group can be added to the stock portfolio if the number of stocks in the first group is less than a minimum. In this study, the minimum number of stocks in the stock portfolio was considered five stocks, but in all cases, the number of stocks in the stock portfolio was more than five. Therefore, adding the stocks of the second group to the stock portfolio is not necessary. The researcher and investor agreement determined the limiting profiles and parameters in ELECTRE-TRI and FlowSort (Table 6). 
Table 4 Stock industry groups

\begin{tabular}{ll}
\hline Alternative & Industry \\
\hline A1 & Fabricated metal products \\
A2 & Telecommunications \\
A3, A5, A9, A22, A23, A24, A39, A49 & Automobile and parts \\
A4, A29 & Electrical equipment \\
A6, A42 & Rubber \& plastic products \\
A7, A16, A41, A45, A46 & Extraction of metal ores \\
A8 & Tile and ceramic \\
A10, A11, A12, A13, A30 & Chemical products \\
A14, A40 & Engineering \\
A15, A37 & Food \& beverage products \\
A17 & Oil and gas extraction (except exploration) \\
A18 & Computer \\
A19, A20, A38 & Manufacture of pharmaceuticals \\
A21 & Financial intermediation \\
A25, A26, A27, A28 & Cement, lime \& plaster \\
A31 & Non-metallic mineral products \\
A32, A33, A34, A35, A36, A47, A48 & Base metals \\
A43 & Communication equipment \\
A44 & Non-ferrous precious metals \\
A50 & Oil products \\
\hline
\end{tabular}

The classification results after solving the problem are presented in "Appendix 3". Based on Table 17, a total of 19 approaches were available, with four approaches for ELECTRE-TRI. These approaches include pessimistic assignment considering the veto threshold, pessimistic assignment without considering the veto threshold, optimistic assignment considering the veto threshold, and optimistic assignment without considering the veto threshold. The FlowSort method considered five well-known preference functions. These preference functions include usual, U-shape, V-shape, $\mathrm{V}$-shape with indifference, and the level. For each preference function, three types of assignments were used. The assignment procedure used in this research is based on the leaving flow $\left(\Phi^{+}\right)$, entering flow $\left(\Phi^{-}\right)$, and net flow $(\Phi)$. As the first group includes the best stocks, this group is considered a stock portfolio. Table 7 shows the stock portfolio created by each approach.

Several studies have examined ranking methods and validated their results (Pamucar et al. 2017; Mukhametzyanov and Pamucar 2018; Biswas et al. 2019; Pamučar et al. 2021). Correlation coefficients of the ranking results obtained using the proposed and previous methods are often calculated. According to the obtained correlation coefficient, the validity of the proposed model is examined. As the correlation coefficient increases, the proposed method's validity also increases. A few studies have validated the results of multi-criteria classification methods. The validation method in the present study is inferred from the validation method used by Xidonas et al. (2009b). In the present study, the validation formula is defined by Eq. (24). Table 8 shows the 
Table 5 Weight of criteria

\begin{tabular}{ll}
\hline Criteria & Weight \\
\hline Return & 0.207 \\
Beta & 0.207 \\
Net profit margin & 0.098 \\
ROA & 0.041 \\
ROE & 0.065 \\
EPS & 0.144 \\
P/E & 0.14 \\
P/BV & 0.098 \\
\hline
\end{tabular}

Table 6 Parameters of ELECTRE-TRI and FlowSort

\begin{tabular}{lllllllll}
\hline Parameters & Return & Beta & $\begin{array}{l}\text { Net Profit } \\
\text { Margin }\end{array}$ & ROA & ROE & EPS & P/E & P/BV \\
\hline Indifference threshold & 5 & 0.05 & 3 & 3 & 3 & 50 & 0.5 & 0.4 \\
Preference threshold & 15 & 0.15 & 8 & 6 & 8 & 300 & 1.5 & 1.2 \\
Veto threshold & 180 & 0.8 & 80 & 50 & 50 & 1000 & 4 & 4 \\
Profile 1 & 50 & 0.6 & 25 & 20 & 30 & 400 & 5.5 & 4 \\
Profile 2 & 20 & 0.9 & 10 & 10 & 15 & 50 & 8 & 6 \\
\hline
\end{tabular}

values of $F$ for primary results. Notably, the effectiveness index $(F)$ is obtained by real return in the next period (2015) (Table 9). The $F$ index indicates the percentage of stocks with more than the average return (Eq. (24)). The return criterion in Tables 3 and 8 refers to the average real return in 2011-2014 and in 2015, respectively. In this study, the return criterion in Table 9 has been used to evaluate the classification results.

As shown in Table 8, the FlowSort presents the best initial result when considering the $\mathrm{V}$-shape preference function and the leaving flow assignment. ELECTRE-TRI presents the best initial result when pessimistic assignment procedure without veto threshold is considered.

The sensitivity analysis aims to overcome the effect of the probable inappropriate amount of parameters and profiles. Therefore, a comprehensive sensitivity analysis was performed on the best results. The sensitivity analysis was conducted on the weight of criteria, first limiting profile, preference thresholds, indifference thresholds, and cutting level. As any change in sensitivity analysis changes the stock portfolio, F's value will also change. Therefore, in all cases, the value of $F$ is calculated.

\section{Influence of changing criteria weights on the results obtained by ELECTRE-TRI}

Sorting results mostly depend on the weight of the criteria (Pamucar et al. 2017). According to Table 10, 18 scenarios for changing the criteria weight are considered. Scenario one is the weights obtained in this study. In scenarios two to nine, the weights of 


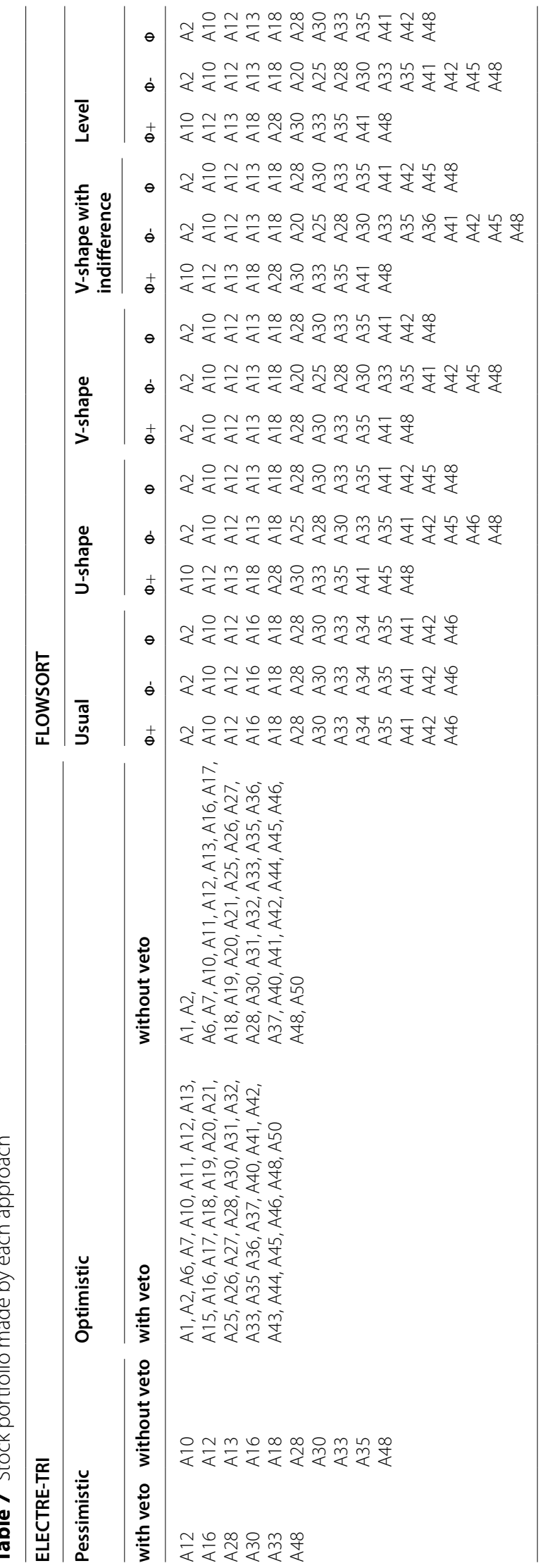


Table 8 Values of F based on different approaches of ELECTRE-TRI and FlowSort

\begin{tabular}{|c|c|c|c|}
\hline Sorting method & & Approach & Value of $F$ \\
\hline \multirow[t]{4}{*}{ ELECTRE-TRI } & \multirow[t]{2}{*}{ Pessimistic } & With veto threshold & 16.7 \\
\hline & & Without veto threshold & 40.0 \\
\hline & \multirow[t]{2}{*}{ Optimistic } & With veto threshold & 34.3 \\
\hline & & Without veto threshold & 36.4 \\
\hline \multirow[t]{15}{*}{ FLOWSORT } & \multirow[t]{3}{*}{ Usual } & $\Phi+$ & 30.8 \\
\hline & & $\Phi-$ & 30.8 \\
\hline & & $\Phi$ & 30.8 \\
\hline & \multirow[t]{3}{*}{ U-shape } & $\Phi+$ & 40.0 \\
\hline & & $\Phi-$ & 33.3 \\
\hline & & $\Phi$ & 38.5 \\
\hline & \multirow[t]{3}{*}{ V-shape } & $\Phi+$ & 45.5 \\
\hline & & $\Phi-$ & 40.0 \\
\hline & & $\Phi$ & 41.7 \\
\hline & \multirow[t]{3}{*}{ V-shape with indifference } & $\Phi+$ & 40.0 \\
\hline & & $\Phi-$ & 37.5 \\
\hline & & $\Phi$ & 38.5 \\
\hline & \multirow[t]{3}{*}{ Level } & $\Phi+$ & 40.0 \\
\hline & & $\Phi-$ & 40.0 \\
\hline & & $\Phi$ & 41.7 \\
\hline
\end{tabular}

Best values are in bold

the first to eighth criteria are set to zero, respectively. The criterion weight is divided equally among the other criteria. In these scenarios, we have examined the effect of eliminating each of these criteria on the final classification. In scenario 10, the weights of all criteria are considered the same. In scenarios 11 to 18 , the weight of criteria one to eight is considered higher than the initial value, respectively. The results of changing criteria weights showed that if the weight of the ROA or P/E had increased to 0.35 , a better stock portfolio would have been obtained.

\section{Influence of changing criteria weights on the results obtained by FlowSort}

Similar to ELECTRE-TRI, the same scenarios are considered for FlowSort. According to Table 10, eliminating ROA or ROE does not change the stock portfolio. If the weight of the P/BV increases to 0.35 , then the worst results are obtained. According to Table 10, changes in the weight of criteria have not improved the stock portfolio. The change in the weight of the P/BV shows that the worst value of $F$ is related to the scenario, in which the weight of the $\mathrm{P} / \mathrm{BV}$ increased. In this case, the value of $F$ has reached 0.1875 , which is the lowest value in the total sensitivity analysis performed in this study. From another aspect, the results of changing the weight of P/BV in ELECTRE-TRI also show that eliminating $\mathrm{P} / \mathrm{BV}$ did not worsen the value of $F$. Increasing the weight of $\mathrm{P} / \mathrm{BV}$ in ELECTRETRI has also made the value of $F$ worse. Therefore, according to the results obtained by two methods, less weight could have been assigned to P/BV. 
Table 9 Real return in the next period

\begin{tabular}{|c|c|c|c|}
\hline Alternative & Return & Alternative & Return \\
\hline A1 & 6.18 & A26 & -26.43 \\
\hline$A 2$ & 12.90 & A27 & -26.08 \\
\hline A3 & -0.62 & A28 & -30.42 \\
\hline A4 & 51.90 & A29 & -26.26 \\
\hline A5 & 20.25 & A30 & -1.22 \\
\hline A6 & -1.28 & A31 & -38.90 \\
\hline A7 & -11.30 & A32 & -29.61 \\
\hline A8 & -65.73 & A33 & -37.62 \\
\hline A9 & 47.11 & A34 & -28.77 \\
\hline A10 & 14.38 & A35 & -16.11 \\
\hline A11 & -33.31 & A36 & -21.02 \\
\hline A12 & -29.42 & A37 & 27.78 \\
\hline A13 & 5.52 & A38 & -4.59 \\
\hline A14 & 23.65 & A39 & 0.45 \\
\hline A15 & -12.33 & A40 & -17.40 \\
\hline A16 & -32.60 & A41 & -28.20 \\
\hline A17 & -33.29 & A42 & -38.96 \\
\hline A18 & 22.59 & A43 & -11.08 \\
\hline A19 & -3.06 & A44 & -22.41 \\
\hline$A 20$ & 37.39 & A45 & -47.01 \\
\hline A21 & 52.38 & A46 & -21.39 \\
\hline A22 & 14.73 & A47 & -50.50 \\
\hline A23 & 37.69 & A48 & -22.52 \\
\hline A24 & 33.32 & A49 & 9.14 \\
\hline A25 & -39.56 & A50 & 7.38 \\
\hline Average return & & & -7.69 \\
\hline
\end{tabular}

Influence of changing the profile on the results obtained by ELECTRE-TRI

In this study, stock portfolio formation is based on the alternatives available in the first class; therefore, we examine the effect of change in the first limiting profile. By increasing the first limiting profile values, the number of alternatives in the first class usually decreases. On the contrary, decreasing the values of the first limiting profile usually increases the number of alternatives in the first class. The first row of Table 11 shows the initial values of the first limiting profile, in which different degrees of changes in the first limiting profile are considered. Due to their cost nature, the changes on the beta, $\mathrm{P} / \mathrm{E}$, and $\mathrm{P} / \mathrm{BV}$ criteria have been done in contrast to the other criteria. According to Table 11, the only scenario that has improved the stock portfolio is when the first limiting profile values increase by $10 \%$.

\section{Influence of changing the profile on the results obtained by FlowSort}

According to Table 11, by increasing the values of the first profile to $5 \%$ or $10 \%$, the value of $F$ decreases slightly. However, with a large increase in first limiting profile values, the worst results are obtained. From another aspect, by reducing the values of the first limiting profile, the same results are obtained in all cases. The value of $F$ decreases by approximately 0.1 , which means that a worse stock portfolio is obtained. 
Table 10 Sensitivity analysis on the weight of criteria

\begin{tabular}{lllllllllll}
\hline No & Return & Beta & $\begin{array}{l}\text { Net Profit } \\
\text { Margin }\end{array}$ & ROA & ROE & EPS & P/E & P/BV & $\begin{array}{l}\text { ELECTRE-TRI } \\
\text { F Value }\end{array}$ & $\begin{array}{l}\text { FlowSort } \\
\text { F Value }\end{array}$ \\
\hline 1 & 0.207 & 0.207 & 0.098 & 0.041 & 0.065 & 0.144 & 0.14 & 0.098 & 0.4 & 0.4545 \\
2 & 0 & 0.237 & 0.128 & 0.071 & 0.095 & 0.174 & 0.17 & 0.128 & 0.25 & 0.3333 \\
3 & 0.237 & 0 & 0.128 & 0.071 & 0.095 & 0.174 & 0.17 & 0.128 & 0.227 & 0.25 \\
4 & 0.221 & 0.221 & 0 & 0.055 & 0.079 & 0.158 & 0.154 & 0.122 & 0.3333 & 0.375 \\
5 & 0.213 & 0.213 & 0.104 & 0 & 0.071 & 0.15 & 0.146 & 0.104 & 0.4 & 0.4545 \\
6 & 0.216 & 0.216 & 0.107 & 0.05 & 0 & 0.153 & 0.149 & 0.107 & 0.3333 & 0.4545 \\
7 & 0.228 & 0.228 & 0.119 & 0.062 & 0.086 & 0 & 0.161 & 0.119 & 0.25 & 0.375 \\
8 & 0.227 & 0.227 & 0.118 & 0.061 & 0.085 & 0.164 & 0 & 0.118 & 0.368 & 0.3 \\
9 & 0.221 & 0.221 & 0.112 & 0.055 & 0.079 & 0.158 & 0.154 & 0 & 0.4 & 0.3333 \\
10 & 0.125 & 0.125 & 0.125 & 0.125 & 0.125 & 0.125 & 0.125 & 0.125 & 0.3182 & 0.2631 \\
11 & 0.35 & 0.187 & 0.078 & 0.021 & 0.045 & 0.124 & 0.12 & 0.078 & 0.4 & 0.3571 \\
12 & 0.187 & 0.35 & 0.078 & 0.021 & 0.045 & 0.124 & 0.12 & 0.078 & 0.3333 & 0.4286 \\
13 & 0.171 & 0.171 & 0.35 & 0.005 & 0.029 & 0.108 & 0.104 & 0.062 & 0.385 & 0.3529 \\
14 & 0.163 & 0.163 & 0.054 & 0.35 & 0.021 & 0.1 & 0.096 & 0.054 & 0.4545 & 0.3333 \\
15 & 0.173 & 0.173 & 0.064 & 0.007 & 0.3 & 0.11 & 0.106 & 0.064 & 0.3846 & 0.2222 \\
16 & 0.178 & 0.178 & 0.069 & 0.012 & 0.036 & 0.35 & 0.111 & 0.069 & 0.3333 & 0.3 \\
17 & 0.177 & 0.177 & 0.068 & 0.011 & 0.035 & 0.114 & 0.35 & 0.068 & 0.5 & 0.4 \\
18 & 0.171 & 0.171 & 0.062 & 0.005 & 0.029 & 0.108 & 0.104 & 0.35 & 0.3333 & 0.1875 \\
\hline
\end{tabular}

Table 11 Sensitivity analysis on profile $r_{1}$

\begin{tabular}{|c|c|c|c|c|c|c|c|c|c|c|}
\hline Profile & Return & Beta & $\begin{array}{l}\text { Net Profit } \\
\text { Margin }\end{array}$ & ROA & ROE & EPS & $P / E$ & P/BV & $\begin{array}{l}\text { ELECTRE- } \\
\text { TRI F Value }\end{array}$ & FlowSort F Value \\
\hline r1 & 50 & 0.6 & 25 & 20 & 30 & 400 & 5.5 & 4 & 0.4 & 0.4545 \\
\hline$r 1+5 \%$ & 52.5 & 0.57 & 26.25 & 21 & 31.5 & 420 & 5.225 & 3.8 & 0.375 & 0.4 \\
\hline$r 1+10 \%$ & 55 & 0.54 & 27.5 & 22 & 33 & 440 & 4.95 & 3.6 & 0.4285 & 0.4285 \\
\hline$r 1+15 \%$ & 57.5 & 0.51 & 28.75 & 23 & 34.5 & 460 & 4.675 & 3.4 & 0.3928 & 0.2 \\
\hline$r 1+20 \%$ & 60 & 0.48 & 30 & 24 & 36 & 480 & 4.4 & 3.2 & 0.3928 & 0.25 \\
\hline$r 1-5 \%$ & 47.5 & 0.63 & 23.75 & 19 & 28.5 & 380 & 5.775 & 4.2 & 0.3636 & 0.3571 \\
\hline$r 1-10 \%$ & 45 & 0.66 & 22.5 & 18 & 27 & 360 & 6.05 & 4.4 & 0.3846 & 0.3571 \\
\hline r1-15\% & 42.5 & 0.69 & 21.25 & 17 & 25.5 & 340 & 6.325 & 4.6 & 0.3125 & 0.3571 \\
\hline r1-20\% & 40 & 0.72 & 20 & 16 & 24 & 320 & 6.6 & 4.8 & 0.2941 & 0.3571 \\
\hline
\end{tabular}

Influence of changing preference threshold on the results obtained by ELECTRE-TRI

In general, the preference threshold value should always be greater than the indifference threshold value. Therefore, in all scenarios, the minimum value considered for the preference threshold is greater than the initial value of the indifference threshold. Table 12 shows the sensitivity analysis result. The initial value of the preference threshold is the italics value. In the sensitivity analysis, values more and less than the initial value are considered. As shown in Table 12, increasing the preference threshold value in return to 100 and decreasing the preference threshold value in P/BV have improved the results. Table 12 also shows that the change in the preference threshold did not cause much change in the final results. 
Table 12 Sensitivity analysis on preference threshold

\begin{tabular}{|c|c|c|c|c|c|c|c|c|c|c|c|}
\hline \multirow{2}{*}{$\frac{\text { No }}{1}$} & \multirow{2}{*}{$\begin{array}{l}\text { Criteria } \\
\text { Return }\end{array}$} & \multicolumn{10}{|c|}{ Preference threshold } \\
\hline & & 0 & 7 & 15 & 25 & 40 & 50 & 75 & 100 & 150 & \\
\hline & $\begin{array}{l}\text { ELECTRE-TRI } \\
\text { F value }\end{array}$ & - & 0.4 & 0.4 & 0.4 & 0.455 & 0.455 & 0.417 & 0.417 & 0.385 & \\
\hline & $\begin{array}{l}\text { FlowSort } \\
\text { Fvalue }\end{array}$ & 0.4166 & 0.4166 & 0.4545 & 0.4545 & 0.3846 & 0.3571 & 0.3571 & 0.3846 & 0.3571 & \\
\hline \multirow[t]{3}{*}{2} & Beta & 0 & 0.05 & 0.1 & 0.15 & 0.3 & 0.4 & 0.45 & 0.5 & 0.7 & 1 \\
\hline & $\begin{array}{l}\text { ELECTRE-TRI } \\
\text { F value }\end{array}$ & - & 0.4 & 0.4 & 0.4 & 0.4 & 0.417 & 0.333 & 0.308 & 0.357 & 0.312 \\
\hline & $\begin{array}{l}\text { FlowSort } \\
\text { Fvalue }\end{array}$ & 0.4545 & 0.4545 & 0.4166 & 0.4545 & 0.4545 & 0.3571 & 0.3571 & 0.375 & 0.3125 & 0.2777 \\
\hline \multirow[t]{3}{*}{3} & Net Profit Margin & 0 & 4 & 8 & 12 & 18 & 25 & 50 & 100 & & \\
\hline & $\begin{array}{l}\text { ELECTRE-TRI } \\
\text { F value }\end{array}$ & - & 0.4 & 0.4 & 0.4 & 0.4 & 0.4 & 0.4 & 0.4 & & \\
\hline & $\begin{array}{l}\text { FlowSort } \\
\text { Fvalue }\end{array}$ & 0.4545 & 0.4545 & 0.4545 & 0.4545 & 0.3846 & 0.3846 & 0.3636 & 0.4 & & \\
\hline \multirow[t]{3}{*}{4} & ROA & 0 & 4 & 6 & 10 & 15 & 30 & 50 & & & \\
\hline & $\begin{array}{l}\text { ELECTRE-TRI } \\
\text { F value }\end{array}$ & - & 0.4 & 0.4 & 0.4 & 0.4 & 0.4 & 0.4 & & & \\
\hline & $\begin{array}{l}\text { FlowSort } \\
\text { Fvalue }\end{array}$ & 0.4545 & 0.4545 & 0.4545 & 0.4545 & 0.4545 & 0.4545 & 0.4545 & & & \\
\hline \multirow[t]{3}{*}{5} & ROE & 0 & 4 & 6 & 8 & 12 & 18 & 25 & 50 & 100 & \\
\hline & $\begin{array}{l}\text { ELECTRE-TRI } \\
\text { F value }\end{array}$ & - & 0.4 & 0.4 & 0.4 & 0.4 & 0.4 & 0.4 & 0.4 & 0.4 & \\
\hline & $\begin{array}{l}\text { FlowSort } \\
\text { Fvalue }\end{array}$ & 0.4 & 0.4545 & 0.4545 & 0.4545 & 0.4545 & 0.4 & 0.4166 & 0.4545 & 0.4545 & \\
\hline \multirow[t]{3}{*}{6} & EPS & 0 & 100 & 150 & 300 & 500 & 800 & 1000 & 2000 & 5000 & \\
\hline & $\begin{array}{l}\text { ELECTRE-TRI } \\
\text { F value }\end{array}$ & - & 0.4 & 0.4 & 0.4 & 0.4 & 0.4 & 0.4 & 0.4 & 0.4 & \\
\hline & $\begin{array}{l}\text { FlowSort } \\
\text { Fvalue }\end{array}$ & 0.4545 & 0.4545 & 0.4545 & 0.4545 & 0.3571 & 0.3571 & 0.3571 & 0.3846 & 0.5555 & \\
\hline \multirow[t]{3}{*}{7} & $\mathrm{P} / \mathrm{E}$ & 0 & 0.5 & 0.8 & 1.5 & 2 & 2.5 & 3 & 4 & & \\
\hline & $\begin{array}{l}\text { ELECTRE-TRI } \\
\text { F value }\end{array}$ & - & 0.333 & 0.333 & 0.4 & 0.4 & 0.379 & 0.384 & 0.384 & & \\
\hline & $\begin{array}{l}\text { FlowSort } \\
\text { Fvalue }\end{array}$ & 0.3636 & 0.3636 & 0.333 & 0.4545 & 0.4545 & 0.4545 & 0.4166 & 0.3846 & & \\
\hline \multirow[t]{3}{*}{8} & $\mathrm{P} / \mathrm{BV}$ & 0 & 0.5 & 0.6 & 0.8 & 1.2 & 1.5 & 2 & & & \\
\hline & $\begin{array}{l}\text { ELECTRE-TRI } \\
\text { F value }\end{array}$ & - & 0.444 & 0.444 & 0.4 & 0.4 & 0.4 & 0.4 & & & \\
\hline & $\begin{array}{l}\text { FlowSort } \\
\text { Fvalue }\end{array}$ & 0.3636 & 0.4545 & 0.4545 & 0.4545 & 0.4545 & 0.4545 & 0.4545 & & & \\
\hline
\end{tabular}

\section{Influence of changing preference threshold on the results obtained by FlowSort}

Given that the best initial result in FlowSort was obtained using the V-shape preference function, we do not consider the indifference threshold parameter in this case. Therefore, we do not have a low threshold limit, and the minimum value of the preference threshold can be zero. Thus, more scenarios are considered in comparison with the sensitivity analysis performed on the preference threshold in ELECTRE-TRI. The changes in the preference threshold value on the EPS criterion indicate that increasing 
Table 13 Sensitivity analysis on the indifference threshold in ELECTRE-TRI

\begin{tabular}{|c|c|c|c|c|c|c|c|c|}
\hline \multirow{2}{*}{$\frac{\text { No }}{1}$} & \multirow{2}{*}{$\begin{array}{l}\text { Criteria } \\
\text { Return }\end{array}$} & \multicolumn{7}{|c|}{ Indifference threshold } \\
\hline & & 0 & 1 & 3 & 5 & 8 & 12 & \\
\hline & F value & 0.4 & 0.4 & 0.4 & 0.4 & 0.4 & 0.4 & \\
\hline \multirow[t]{2}{*}{2} & Beta & 0 & 0.02 & 0.05 & 0.08 & 0.1 & 0.15 & \\
\hline & Fvalue & 0.393 & 0.4 & 0.4 & 0.4 & 0.4 & 0.3 & \\
\hline \multirow[t]{2}{*}{3} & Net Profit Margin & 0 & 1.5 & 3 & 5 & 8 & & \\
\hline & Fvalue & 0.4 & 0.4 & 0.4 & 0.4 & 0.4 & & \\
\hline \multirow[t]{2}{*}{4} & $\mathrm{ROA}$ & 0 & 2 & 3 & 4 & 5 & & \\
\hline & Fvalue & 0.4 & 0.4 & 0.4 & 0.4 & 0.4 & & \\
\hline \multirow[t]{2}{*}{5} & ROE & 0 & 1 & 3 & 5 & 8 & & \\
\hline & F value & 0.4 & 0.4 & 0.4 & 0.4 & 0.4 & & \\
\hline \multirow[t]{2}{*}{6} & EPS & 0 & 50 & 100 & 300 & & & \\
\hline & Fvalue & 0.4 & 0.4 & 0.4 & 0.4 & & & \\
\hline \multirow[t]{2}{*}{7} & $\mathrm{P} / \mathrm{E}$ & 0 & 0.25 & 0.5 & 0.75 & 1 & 1.25 & 1.5 \\
\hline & F value & 0.333 & 0.333 & 0.4 & 0.4 & 0.363 & 0.385 & 0.385 \\
\hline \multirow[t]{2}{*}{8} & P/BV & 0 & 0.2 & 0.4 & 0.8 & 1.2 & & \\
\hline & F value & 0.4 & 0.4 & 0.4 & 0.4 & 0.4 & & \\
\hline
\end{tabular}

Table 14 Sensitivity analysis on cutting level $(\lambda)$ in ELECTRE-TRI

\begin{tabular}{llllllllll}
\hline Cutting level $(\boldsymbol{\lambda})$ & $\mathbf{0 . 6}$ & $\mathbf{0 . 6 2 5}$ & $\mathbf{0 . 6 5}$ & $\mathbf{0 . 6 7 5}$ & $\mathbf{0 . 7}$ & $\mathbf{0 . 7 2 5}$ & 0.75 & $\mathbf{0 . 7 7 5}$ & $\mathbf{0 . 8}$ \\
\hline F value & 0.318 & 0.368 & 0.368 & 0.384 & 0.333 & 0.4 & 0.4 & 0.25 & 0.2 \\
\hline
\end{tabular}

the preference threshold value in most cases has resulted in worse results. However, by increasing the preference threshold to 5000 , the best performance for the stock portfolio is achieved (Table 12).

\section{Influence of changing indifference threshold on the results obtained by ELECTRE-TRI}

The indifference threshold allows considering the imprecise nature of the data into the model. Table 13 presents the sensitivity analysis result. The initial value of the indifference threshold is the italics value. In the sensitivity analysis, values more and less than the initial value are considered. In ELECTRE-TRI, in addition to the indifference threshold, the preference threshold is also defined, and the value of the indifference threshold should not be greater than the preference threshold. Thus, this limitation is considered in the sensitivity analysis. The maximum possible values for the indifference threshold are considered in this sensitivity analysis. As shown in Table 13, the change in the indifference threshold has not caused much change to the stock portfolios.

\section{Influence of changing the cutting level on the results obtained by ELECTRE-TRI}

The cutting level is a parameter used in the ELECTRE-TRI method. As shown in Table 14, increasing or decreasing the cutting level did not improve the results. Therefore, the initial value of 0.75 is a good value. Notable, in many studies, the cutting level 
value is 0.75 . Determining the cutting level value properly in the ELECTRE-TRI is very important because determining an inappropriate value for the cutting level can significantly worsen the result.

In this section, sensitivity analysis on the best results obtained by ELECTRE-TRI and FlowSort was presented. The sensitivity analysis was conducted on the weight of criteria, first limiting profile, preference thresholds, indifference thresholds, and cutting level. According to the sensitivity analysis, the best value of $F$ for the FlowSort and ELECTRE-TRI is 55.5 and 50, respectively. FlowSort provided a stock portfolio of 55.5\%, with a stock return higher than the average return of all stocks. The stock portfolio constructed by FlowSort includes the Mobile Telecommunication Company of Iran (A2), Kharg Petrochemical Company (A10), Shiraz Petrochemical Company (A12), Fanavaran Petrochemical Company (A13), Informatics Services Corporation (A18), Gharb Cement (A28), Kermanshah Petrochemical Industries Company (A30), Khouzestan Steel Company (A33), and Khorasan Steel Company (A35) considering sensitivity analysis.

Nemery and Lamboray (2008) stated that working with veto thresholds in ELECTRETRI further increases the difference between optimistic and pessimistic assignments. As shown in Table 8, the difference between optimistic and pessimistic assignments in ELECTRE-TRI was 0.176 . This study confirmed that using the veto threshold increases the difference between two types of assignments. Doumpos and Zopounidis (2002) mentioned that introducing the veto threshold facilitates the development of non-compensatory models. In these models, an alternative's significantly low performance in an evaluation criterion is not compensated by the alternative's performance on the remaining criteria. As shown in Table 8, the worst $F$ value is obtained when the pessimistic approach with the veto threshold was applied in ELECTRE-TRI. A comparison of optimistic approaches also shows that the F value is worse when we apply the veto threshold in ELECTRE-TRI.

\section{Managerial implications}

SPS is an important decision process for investment managers to select stocks from a large pool of stocks. The presented framework in this study can be applied in investment companies to help managers construct a stock portfolio. Applying this framework can help investment managers increase their profitability by using a rational approach and choosing the right stocks in the stock portfolio.

In classic models, two criteria, including the return and risk, were considered. In the real world, investors may have additional concerns (Steuer et al. 2008). Multi-criteria sorting methods can consider multiple conflicting criteria for solving the SPS problems. This study presented an application of two known multi-criteria sorting methods to a real financial problem. The advantage of these methods is that investment managers can easily enter their preferences into these techniques. Among the applied methods in this research, FlowSort allows the use of different preference functions. In addition, FlowSort is more suitable for investment managers who want to be more involved in the modeling and problem-solving process. This study applies the FlowSort in an SPS context for the first time. According to the results of this study, using $\mathrm{V}$-shape or level preference function and using net flow may probably be a better choice for investment managers who intend to apply FlowSort. 
Notably, the framework presented in this study is only for stock selection, so this framework is not applicable for determining asset allocation. To allocate assets, multiobjective or goal programming models can be applied. Another point is that the criteria used to select stocks may not be the same as those required for asset allocation. Therefore, the criteria required for asset allocation are identifiable from the literature and through a survey of experts.

\section{Conclusion}

This study aimed to examine ELECTRE-TRI and FlowSort for SPS, and the analysis was performed based on the real return in the new period. In ELECTRE-TRI, if the results from the pessimistic approach are very different from the optimistic approach, then several incompatibilities exist between an alternative and the profiles of the categories. The results obtained from the ELECTRE-TRI show a situation of incomparability in several cases (A17, A19, A21, A26, A31, A35, A40, A44, and A50). According to the optimistic or pessimistic approach, nine alternatives are allocated to the best (first) or worse (third) class but not to the intermediate (second) class. In all these cases, evidence to support the assignments is not enough. Thus, more information might be needed to properly assign these alternatives, such as including other decision criteria or providing precise evaluations. The result also shows that using the veto threshold for ELECTRETRI does not produce a good result for that SPS problem. The reason may be the nature of the SPS problem and its compatibility with non-compensatory models. We suggest that other researchers refrain from using veto thresholds in this kind of problem. The results obtained by FlowSort show that this method can create a better portfolio when $\mathrm{V}$-shape or level preference function is applied. This research used three types of outranking flow, namely, leaving, entering, and net flow, for FlowSort. In the FlowSort, no high difference exists between leaving and entering flow results for all alternatives. This study showed that when the FlowSort uses the net flow assignment approach, regardless of the type of preference function, a very high similarity is visible between the stock portfolios obtained. Therefore, we can conclude that using the net flow approach helps to achieve more reliable results. One of the limitations of the research is the lack of stock market stability. The results showed that stocks performed poorly in the three years but had a very good return in the next period, such as stocks in the automobile and parts industry group. A longer period for real return can increase the evaluation's accuracy. This study also highlighted the importance of correctly defining the parameter values. In recent studies, researchers proposed some approaches for eliciting thresholds and profiles from examples. These approaches can be compared in future studies.

\section{Appendix 1}

See Table 15 
Table 15 Common preference functions (Greco et al. 2016)

\begin{tabular}{ccc}
\hline Type & Function & Parameter \\
\hline Usual & $P(d)= \begin{cases}0 & d \leq 0 \\
1 & d>0\end{cases}$ & \\
& & $P(d)= \begin{cases}0 & d \leq q \\
1 & d>q\end{cases}$
\end{tabular}

Appendix 2

See Table 16.

Table 16 Subjective interpretation of the Silhouette coefficient (Kaufman and Rousseeuw 2009)

Silhouette coefficient

$0.71-1.00$

$0.51-0.70$

$0.26-50$

0.25

\section{Proposed interpretation}

A strong structure has been found

A reasonable structure has been found

The structure is weak and could be artificial

No substantial structure has been found

\section{Appendix 3}

See Table 17. 


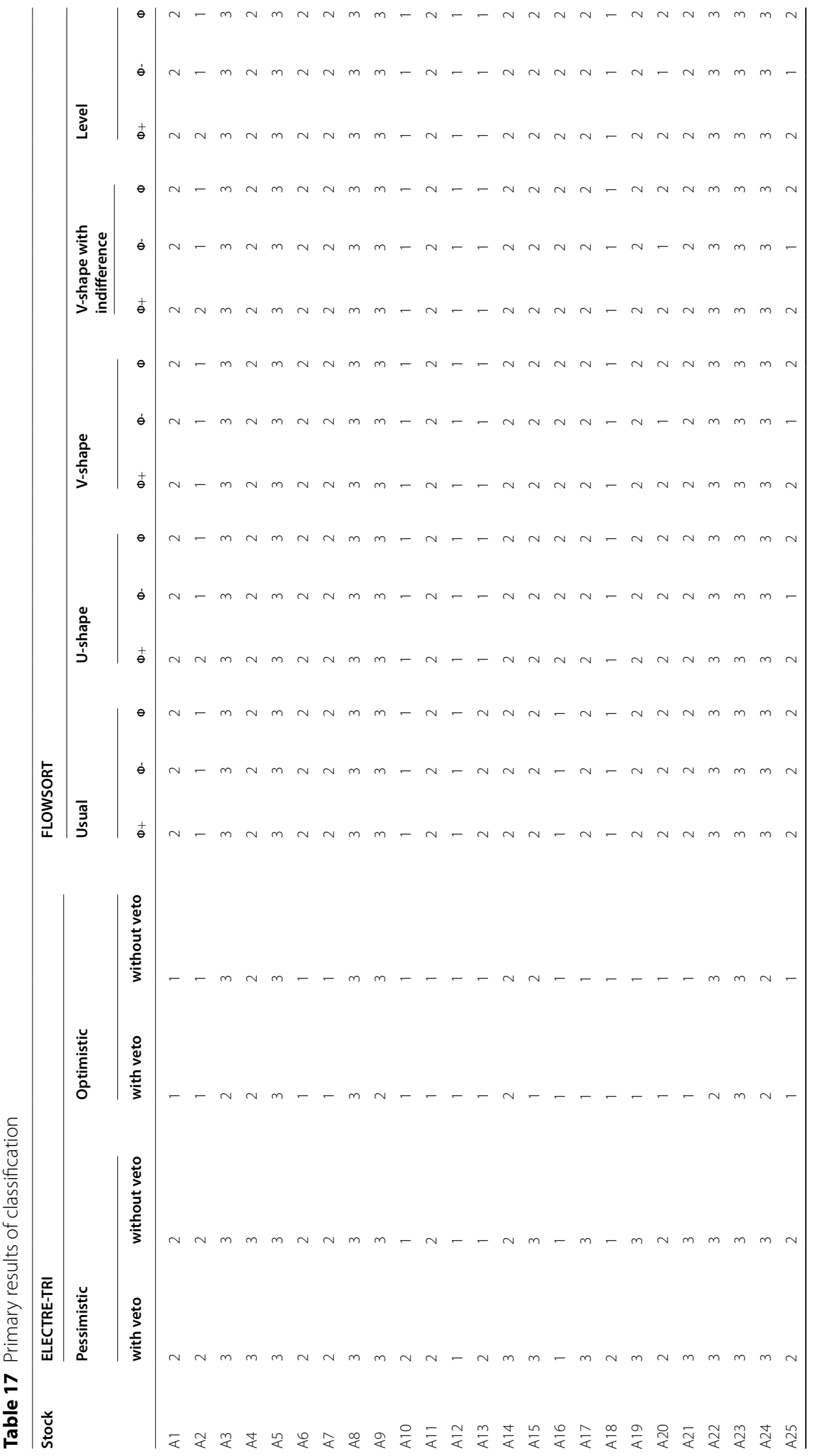




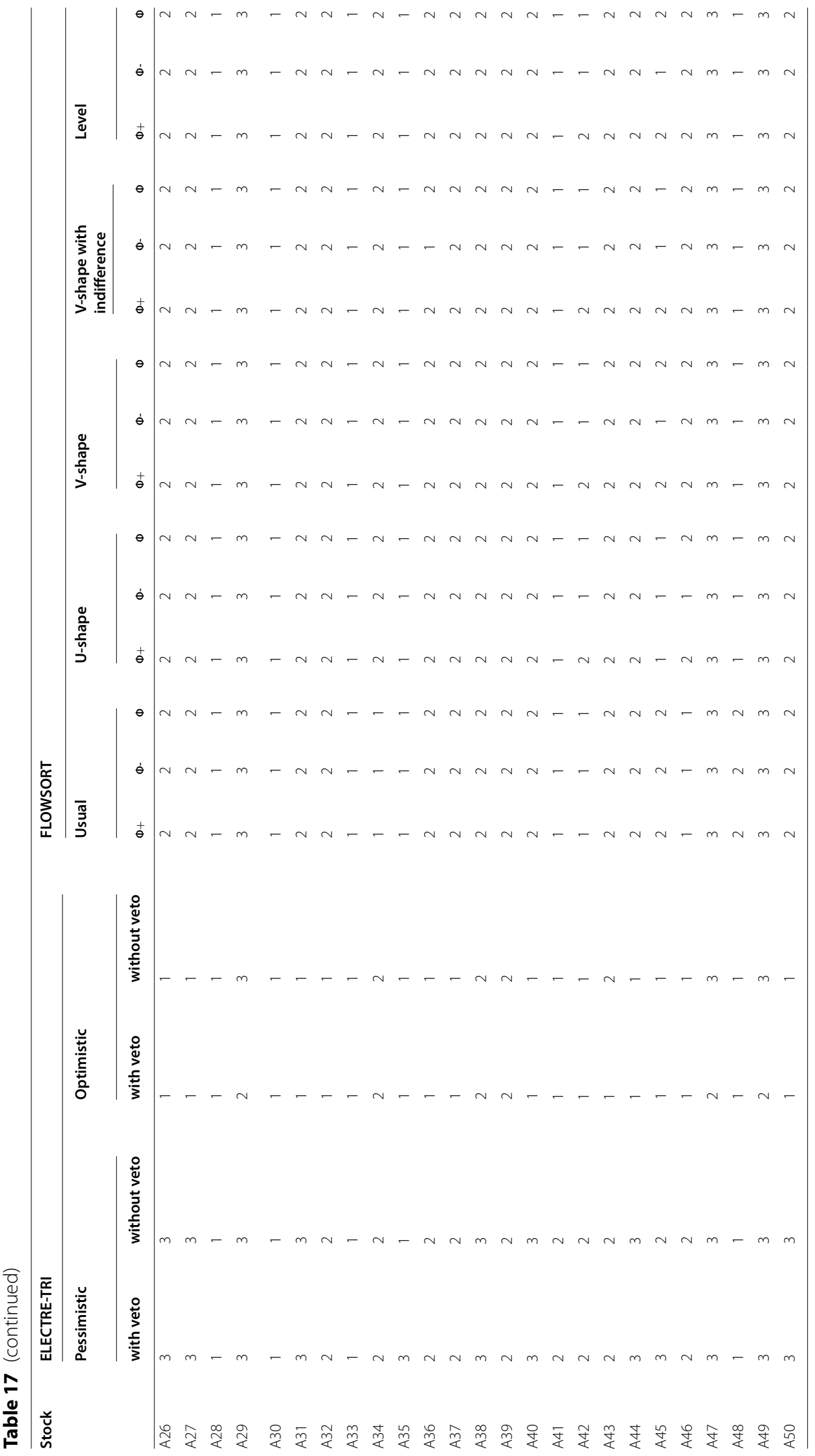




\section{Abbreviations}

EPS: Earnings Per Share; P/E: Price/Earnings ratio;; ROA: Return on Assets; ROE: Return on Equity; P/BV: Price to Book Value: SPS: Stock Portfolio Selection; MPT: Modern Portfolio Theory; DM: Decision-Maker; MCDM: Multi-Criteria Decision-Making; BWM: Best-Worst Method; AHP: Analytic Hierarchy Process; ANP: Analytic Network Process; TOPSIS: Technique for Order of Preference by Similarity to Ideal Solution; VIKOR: VlseKriterijumska Optizacija I Kompromisno Resenje; ELECTRE: ELimination and Choice Expressing Reality; PROMETHEE: Preference Ranking Organization METHod for Enrichment Evaluation; CF: Compound Factor; CA: Cluster Analysis; SC: Silhouette Coefficient.

\section{Acknowledgements}

We acknowledge the anonymous referees for their remarks.

\section{Authors' contributions}

All authors participated in the development of the research. MSMME was the main contributor in the writing of the manuscript and data analysis. CMMM participated in the critical revision of the manuscript. MRM participated in the development of the conceptual idea and supervised the research. MRSM supervised the research and helped in data collection. PN reviewed the theoretical framework and empirical analysis of the research paper. All authors read and approved the final manuscript.

\section{Authors' information}

Mir Seyed Mohammad Mohsen Emamat is a lecturer and Ph.D. candidate in Industrial Management at Allameh Tabataba'i University, Tehran, Iran. He received his MS degree in Industrial Management from the University of Tehran, Tehran, Iran. His research interests include operational research, multi-criteria decision-making, classification problems, and finance. He has served as a reviewer for several national and international journals.

Caroline Maria de Miranda Mota is Associate Professor in the Department of Management Engineering at UFPE, director of the research group on Project Management and Development (PMD) and deputy director of the Brazilian Society of Operations Research (SOBRAPO, term 2016-2021). She obtained her Ph.D. in Management Engineering from UFPE in 2005. Her research interests include Multiple Criteria Decision Making/Aid, public policy decisions, geographic information systems and project management. Her research has been published in about 30 scientific journals, serving as associate editor and reviewer of journals and conferences.

Mohammad Reza Mehregan is a Full Professor at the Department of Industrial Management at University of Tehran, Iran. He received his Ph.D. in Industrial Management from Tarbiat Modares University in Iran. He has over 30 years of teaching experience at graduate and post-graduate levels and has supervised several doctoral theses in the area of operational research and decision-making. His research interests include operational research, decision-making, soft systems analysis, and optimization.

Mohammad Reza Sadeghi Moghadam is currently an Associate Professor in Operation \& Production Management in University of Tehran, Iran. He has published a number of papers in acclaimed journals, such as the Knowledge Based systems, Expert Systems with Applications, International journal of disaster risk reduction, Applied Soft Computing, Total Quality Management \& Business Excellence, and International Journal of Qualitative Method. His research interests are in computational intelligence, cognitive science, supply chain management and quality management.

Philippe Nemery is currently working as data analyst scientist in the private sector. Before, he was a Senior Lecturer at the Department of Mathematics at the University of Portsmouth. He defended his thesis at the Université Libre de Bruxelles (ULB) in 2008 on the following topic: 'On the use of multicriteria ranking methods in sorting problems.' His research activities encompass Multicriteria Decision Aid (MCDA), Ranking and Classification problems, Clustering problems. In 2004, he received a degree as engineer in electro mechanics from the Engineering Faculty at the ULB. He was the coorganiser of a special stream related to decision making at the 52th Operational Research Society Conference in London, 2010.

\section{Funding}

Not applicable.

Availability of data and materials

The data used for analysis and research findings are presented in the tables of the article itself.

\section{Declarations}

\section{Competing interests}

The authors declare that they have no competing interests.

\section{Author details}

${ }^{1}$ Department of Industrial Management, Faculty of Management and Accounting, Allameh Tabataba'i University, Tehran 14348-63111, Iran. ${ }^{2}$ Universidade Federal de Pernambuco, Recife, Brazil. ${ }^{3}$ University of Tehran, Tehran, Iran. ${ }^{4}$ SAP BeLux, Brussels, Belgium.

Received: 23 April 2021 Accepted: 14 November 2021

Published online: 03 February 2022

\section{References}

Abdelaziz FB, Aouni B, El FR (2007) Multi-objective stochastic programming for portfolio selection. Eur J Oper Res. https:// doi.org/10.1016/j.ejor.2005.10.021 
Ameri AA, Pourghasemi HR, Cerda A (2018) Erodibility prioritization of sub-watersheds using morphometric parameters analysis and its mapping: a comparison among TOPSIS, VIKOR, SAW, and CF multi-criteria decision making models. Sci Total Environ 613-614:1385-1400. https://doi.org/10.1016/j.scitotenv.2017.09.210

Amin GR, Hajjami M (2021) Improving DEA cross-efficiency optimization in portfolio selection. Expert Syst Appl. https:// doi.org/10.1016/j.eswa.2020.114280

Aouni B, Doumpos M, Pérez-Gladish B, Steuer RE (2018) On the increasing importance of multiple criteria decision aid methods for portfolio selection. J Oper Res Soc 69:1525-1542. https://doi.org/10.1080/01605682.2018.1475118

Arbelaitz O, Gurrutxaga I, Muguerza J et al (2013) An extensive comparative study of cluster validity indices. Pattern Recognit. https://doi.org/10.1016/j.patcog.2012.07.021

Asgharizadeh E, Taghizadeh Yazdi M, Mohammadi Balani A (2019) An output-oriented classification of multiple attribute decision-making techniques based on fuzzy c-means clustering method. Int Trans Oper Res 26:2476-2493. https://doi.org/10.1111/itor.12449

Atta Mills EFE, Baafi MA, Amowine N, Zeng K (2020) A hybrid grey MCDM approach for asset allocation: evidence from China's Shanghai stock exchange. J Bus Econ Manag. https://doi.org/10.3846/jbem.2020.11967

Belacel N (2000) Multicriteria assignment method PRO AFTN: methodology and medical application. Eur J Oper Res 125:175-183. https://doi.org/10.1016/S0377-2217(99)00192-7

Belacel N, Boulassel MR (2004) Multicriteria fuzzy classification procedure PROCFTN: Methodology and medical application. Fuzzy Sets Syst 141:203-217. https://doi.org/10.1016/S0165-0114(03)00022-8

Biswas S, Bandyopadhyay G, Guha B, Bhattacharjee M (2019) An ensemble approach for portfolio selection in a multicriteria decision making framework. Decis Mak Appl Manag Eng 2:138-158. https://doi.org/10.31181/dmame $2003079 b$

Bouri A, Martel JM, Chabchoub H (2002) A multi-criterion approach for selecting attractive portfolio. J Multi-Criteria Decis Anal 11:269-277. https://doi.org/10.1002/mcda.334

Brans JP, Vincke P (1985) Note-a preference ranking organisation method. Manag Sci 31:647-656. https://doi.org/10. 1287/mnsc.31.6.647

Brito AJ, de Almeida AT, Mota CMM (2010) A multicriteria model for risk sorting of natural gas pipelines based on ELECTRE TRl integrating Utility Theory. Eur J Oper Res 200:812-821. https://doi.org/10.1016/j.ejor.2009.01.016

Campos ACSM, Mareschal B, De Almeida AT (2015) Fuzzy FlowSort: an integration of the FlowSort method and Fuzzy Set Theory for decision making on the basis of inaccurate quantitative data. Inf Sci (ny) 293:115-124. https://doi.org/ 10.1016/j.ins.2014.09.024

Certa A, Enea M, Galante GM, La Fata CM (2017) ELECTRE TRI-based approach to the failure modes classification on the basis of risk parameters: An alternative to the risk priority number. Comput Ind Eng 108:100-110. https://doi.org/ 10.1016/j.cie.2017.04.018

Davies DL, Bouldin DW (1979) A cluster separation measure. IEEE Trans Pattern Anal Mach Intell PAMI-1:224-227. https:// doi.org/10.1109/TPAMI.1979.4766909

de Araújo MCB, Alencar LH, de Miranda Mota CM (2021) Classification model for bid/no-bid decision in construction projects. Int Trans Oper Res. https://doi.org/10.1111/itor.13037

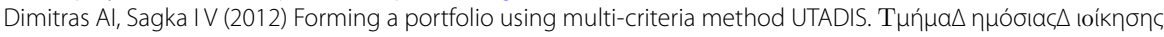
1:116-132

Dominiak C (1997) Portfolio selection using the idea of reference solution. In: Fandel G, Gal T (eds) Multiple criteria decision making. Springer, Berlin, pp 593-602

Doumpos M, Zopounidis C (2002) Multi-criteria classification methods in financial and banking decisions. Int Trans Oper Res 9:567-581. https://doi.org/10.1111/1475-3995.00374

Doumpos M, Zopounidis C, Fragiadakis P (2016) Assessing the financial performance of European banks under stress testing scenarios: a multicriteria approach. Oper Res 16:197-209. https://doi.org/10.1007/s12351-015-0192-y

Ehrgott M, Klamroth K, Schwehm C (2004) An MCDM approach to portfolio optimization. Eur J Oper Res 155:752-770. https://doi.org/10.1016/S0377-2217(02)00881-0

Fernández E, Fiqueira JR, Navarro J, Roy B (2017) ELECTRE TRI-nB: a new multiple criteria ordinal classification method. Eur J Oper Res. https://doi.org/10.1016/j.ejor.2017.04.048

Figueira J, Greco S, Ehrgott M (2005) Multiple criteria decision analysis: state of the art surveys. Springer, Berlin

Gan G, Ma C, Wu J (2007) Data clustering: theory, algorithms, and applications. SIAM, Philadelphia

Gomes L, Santos LL (2008) An application of The ELECTRE TRI method to human resource management in telecommunication in Brasil. Rio's Int J Sci Ind Syst Eng Manag 2:1-20

Govindan K, Jepsen MB (2016) Supplier risk assessment based on trapezoidal intuitionistic fuzzy numbers and ELECTRE TRI-C: a case illustration involving service suppliers. J Oper Res Soc 67:339-376. https://doi.org/10.1057/jors.2015. 51

Greco S, Ehrgott M, Fiqueira JR (2016) Multiple criteria decision analysis. Springer, New York

Gupta P, Mehlawat MK, Saxena A (2013) Hybrid optimization models of portfolio selection involving financial and ethical considerations. Knowledge-Based Syst 37:318-337. https://doi.org/10.1016/j.knosys.2012.08.014

Gupta S, Bandyopadhyay G, Biswas S, Upadhyay A (2019) A hybrid machine learning and dynamic nonlinear framework for determination of optimum portfolio structure. In: Lecture notes in networks and systems

Hargreaves CA (2013) Stock portfolio selection using data mining approach. IOSR J Eng 3:42-48. https://doi.org/10.9790/ 3021-031114248

Hodgett RE (2016) Comparison of multi-criteria decision-making methods for equipment selection. Int J Adv Manuf Technol 85:1145-1157. https://doi.org/10.1007/s00170-015-7993-2

Huang X (2008) Portfolio selection with a new definition of risk. Eur J Oper Res 186:351-357. https://doi.org/10.1016/j. ejor.2007.01.045

Hurson C, Ricci-Xella N (1998) Multicriteria decision making and portfolio management with arbitrage pricing theory. In: Operational tools in the management of financial risks

Hurson C, Ricci-Xella N (2002) Structuring portfolio selection criteria for interactive decision support. Eur Res Stud J 5:69-94 
Hurson C, Zopounidis C (1997) On the use of multicriteria decision aid methods to portfolio selection. In: Clímaco J (ed) Multicriteria analysis. Springer, Berlin Heidelberg, pp 496-507

Hwang C-L, Yoon K (1981) Multiple attribute decision making-methods and applications. Springer, Berlin

Ishizaka A, Nemery P (2013) Multi-criteria decision analysis: methods and software. Wiley, New York

Janssen P, Nemery P (2013) An extension of the FlowSort sorting method to deal with imprecision. 4OR 11:171-193. https://doi.org/10.1007/s10288-012-0219-7

Jerry Ho WR, Tsai CL, Tzeng GH, Fang SK (2011) Combined DEMATEL technique with a novel MCDM model for exploring portfolio selection based on CAPM. Expert Syst Appl 38:16-25. https://doi.org/10.1016/j.eswa.2010.05.058

Kadim A, Sunardi N, Husain T (2020) The modeling firm's value based on financial ratios, intellectual capital and dividend policy. Accounting. https://doi.org/10.5267/j.ac.2020.5.008

Kaufman L, Rousseeuw PJ (2009) Finding groups in data: an introduction to cluster analysis. Wiley, New York

Kazemi A, Sarrafha K, Beedel M (2014) A hybrid fuzzy decision making method for a portfolio selection: a case study of Tehran Stock Exchange. Int J Ind Syst Eng 18:335-354. https://doi.org/10.1504/IJSE.2014.065537

Kou G, Xiao H, Cao M, Lee LH (2021) Optimal computing budget allocation for the vector evaluated genetic algorithm in multi-objective simulation optimization. Automatica. https://doi.org/10.1016/j.automatica.2021.109599

La Fata CM, Giallanza A, Micale R, La Scalia G (2021) Ranking of occupational health and safety risks by a multi-criteria perspective: inclusion of human factors and application of VIKOR. Saf Sci. https://doi.org/10.1016/j.ssci.2021.105234

Lee SM, Lerro AJ (1973) Optimizing the portfolio selection for mutual funds. J Finance 28:1087. https://doi.org/10.2307/ 2978750

Li T, Kou G, Peng Y, Yu PS (2021) An integrated cluster detection, optimization and interpretation approach for financial data. IEEE Trans Cybern. https://doi.org/10.1109/TCYB.2021.3109066

Lintner J (1965) The valuation of risk assets and the selection of risky investments in stock Portfolios and Capital Budgets. Rev Econ Stat. https://doi.org/10.2307/1924119

MacQueen J (1967) Some methods for classification and analysis of multivariate observations. In: Proceedings of the fifth berkeley symposium on mathematical statistics and probability, Volume 1: Statistics. University of California Press, Berkeley, Calif., pp 281-297

Mansour N, Cherif MS, Abdelfattah W (2019) Multi-objective imprecise programming for financial portfolio selection with fuzzy returns. Expert Syst Appl 138:112810. https://doi.org/10.1016/j.eswa.2019.07.027

Markowitz H (1952) Portfolio selection. J Finance 7:77-91. https://doi.org/10.1111/j.1540-6261.1952.tb01525.x

Mary SASA, Suganya G (2016) Multi-criteria decision making using ELECTRE. Circuits Syst 07:1008-1020. https://doi.org/ 10.4236/cs.2016.76085

Mehregan MR, Sadeghi Moghadam MR, Emamat MSMM (2018) Applying the clustering and UTADIS models to form an investment portfolio. Financ Res J 20:53-74. https://doi.org/10.22059/fr.2018.253452.1006622

Mehregan MR, Sadeghi-Moghadam MR, Emamat MSMM (2019) Stock portfolio selection by ELECTRE-TRI: Abilities, approaches and sensitivity analysis. Financ Manag Strateg 7:1-32. https://doi.org/10.22051/ffm.2018.16248.1424

Mendas A, Mebrek A, Mekranfar Z (2020) Comparison between two multicriteria methods for assessing land suitability for agriculture: application in the area of Mleta in western part of Algeria. Environ Dev Sustain. https://doi.org/10. 1007/s10668-020-01012-5

Micale R, Giallanza A, Puma GL, la Scalia G (2019a) A proposal for sorting a projects portfolio through the ELECTRE TRI method focused on the European strategy. J Mod Proj Manag. https://doi.org/10.19255/JMPM02104

Micale R, La Fata CM, La Scalia G (2019b) A combined interval-valued ELECTRE TRI and TOPSIS approach for solving the storage location assignment problem. Comput Ind Eng. https://doi.org/10.1016/j.cie.2019.06.011

Mousseau V, Figueira J, Naux JP (2001) Using assignment examples to infer weights for ELECTRE TRI method: Some experimental results. Eur J Oper Res 130:263-275. https://doi.org/10.1016/S0377-2217(00)00041-2

Mukhametzyanov I, Pamucar D (2018) A sensitivity analysisin mcdm problems: a statistical approach. Decis Mak Appl Manag Eng 1:51-80. https://doi.org/10.31181/dmame1802050m

Mulliner E, Malys N, Maliene V (2016) Comparative analysis of MCDM methods for the assessment of sustainable housing affordability. Omega (united Kingdom) 59:146-156. https://doi.org/10.1016/j.omega.2015.05.013

Nemery P, Lamboray C (2008) Flow\$mathcal\{S\}\$ort: a flow-based sorting method with limiting or central profiles. TOP 16:90-113. https://doi.org/10.1007/s11750-007-0036-x

Nowak M (2004) Preference and veto thresholds in multicriteria analysis based on stochastic dominance. Eur J Oper Res 158:339-350. https://doi.org/10.1016/j.ejor.2003.06.008

Opricovic S, Tzeng GH (2004) Compromise solution by MCDM methods: A comparative analysis of VIKOR and TOPSIS. Eur J Oper Res 156:445-455. https://doi.org/10.1016/S0377-2217(03)00020-1

Pamučar D, Žižović M, Biswas S, Božanić D (2021) A new logarithm methodology of additive weights (LMAW) for multicriteria decision-making: application in logistics. FACTA Univ 21. https://doi.org/10.22190/FUME210214031P

Pamucar DS, Božanic D, Randelovic A (2017) Multi-criteria decision making: an example of sensitivity analysis. Serbian J Manag 12:1-27. https://doi.org/10.5937/sjm12-9464

Parkan C, Wu ML (2000) Comparison of three modern multicriteria decision-making tools. Int J Syst Sci 31:497-517. https://doi.org/10.1080/002077200291082

Pereira DV, Mota CMM (2016) Human development index based on ELECTRE TRI-C multicriteria method: an application in the City of Recife. Soc Indic Res 125:19-45. https://doi.org/10.1007/s11205-014-0836-y

Perold AF (1984) Large-scale portfolio optimization. Manage Sci. https://doi.org/10.1287/mnsc.30.10.1143

Qu G, Qu W, Wang J et al (2018) Factorial-quality scalar and an extension of ELECTRE in intuitionistic fuzzy sets. Int J Inf Technol Decis Mak 17:183-207. https://doi.org/10.1142/S0219622017500389

Rahiminezhad Galankashi M, Mokhatab Rafiei F, Ghezelbash M (2020) Portfolio selection: a fuzzy-ANP approach. Financ Innov 6:17. https://doi.org/10.1186/s40854-020-00175-4

Ramezanian R (2019) Estimation of the profiles in posteriori ELECTRE TRI: a mathematical programming model. Comput Ind Eng 128:47-59. https://doi.org/10.1016/j.cie.2018.12.034

Rezaei J (2015) Best-worst multi-criteria decision-making method. Omega (united Kingdom) 53:49-57. https://doi.org/10 1016/j.omega.2014.11.009 
Rezaei J (2020) A concentration ratio for nonlinear best worst method. Int J Inf Technol Decis Mak 19:891-907. https:// doi.org/10.1142/S0219622020500170

Rezaeian J, Akbari F (2015) Stock portfolio selection using a hybrid fuzzy approach: a case study in Tehran stock exchange. Int J Oper Res. https://doi.org/10.1504/IJOR.2015.068560

Rist M, Pizzica AJ (2015) Financial ratios for executives

Rogers MG, Bruen M, Maystre L-Y (2013) Electre and decision support: methods and applications in engineering and infrastructure investment. Springer, Berlin

Ross SA (1976) The arbitrage theory of capital asset pricing. J Econ Theory. https://doi.org/10.1016/0022-0531 (76)90046-6

Roy B (1968) Classement et choix en présence de points de vue multiples. RIRO 2:57-75. https://doi.org/10.1051/ro/ 196802V100571

Roy B (1981) The optimisation problem formulation: Criticism and overstepping. J Oper Res Soc 32:427-436. https://doi. org/10.1057/jors.1981.93

Roy B (1991) The outranking approach and the foundations of electre methods. Theory Decis 31:49-73. https://doi.org/ 10.1007/BF00134132

Roy B, Bouyssou D (1993) Aide multicritère à la décision : méthodes et cas. Economica, Paris

Roy B, Présent M, Silhol D (1986) A programming method for determining which Paris metro stations should be renovated. Eur J Oper Res 24:318-334. https://doi.org/10.1016/0377-2217(86)90054-8

Saaty TL (1977) A scaling method for priorities in hierarchical structures. J Math Psychol 15:234-281. https://doi.org/10. 1016/0022-2496(77)90033-5

Saaty TL (1986) Axiomatic foundation of the analytic hierarchy process. Manag Sci 32:841-855. https://doi.org/10.1287/ mnsc.32.7.841

Saaty TL (1990) How to make a decision: the analytic hierarchy process. Eur J Oper Res 48:9-26. https://doi.org/10.1016/ 0377-2217(90)90057-I

Saaty TL (1996) Decision making with dependence and feedback: the analytic network process. RWS Publication, Pittsburgh

Sharpe WF (1963) A simplified model for portfolio analysis. Manag Sci. https://doi.org/10.1287/mnsc.9.2.277

Sharpe WF (1964) Capital asset prices: a theory of market equilibrium under conditions of risk. J Finance. https://doi.org/ 10.1111/j.1540-6261.1964.tb02865.x

Shen F, Xu J, Xu Z (2016) An outranking sorting method for multi-criteria group decision making using intuitionistic fuzzy sets. Inf Sci (ny) 334-335:338-353. https://doi.org/10.1016/j.ins.2015.12.003

Silva AMR, Sobral MFF (2017) Multicriteria model to sort suppliers in a Brazilian dairy industry. Int I Decis Support Syst Technol 9:42-53. https://doi.org/10.4018/JDSST.2017070103

Silva S, Alçada-Almeida L, Dias LC (2014a) Development of a web-based multi-criteria spatial decision support system for the assessment of environmental sustainability of dairy farms. Comput Electron Agric. https://doi.org/10.1016/j. compag.2014.06.009

Silva S, Alçada-Almeida L, Dias LC (2014b) Biogas plants site selection integrating Multicriteria Decision Aid methods and GIS techniques: A case study in a Portuguese region. Biomass Bioenerg. https://doi.org/10.1016/j.biombioe.2014. 10.025

Steuer RE, Qi Y, Hirschberger M (2008) Portfolio selection in the presence of multiple criteria. In: Zopounidis C, Doumpos M, Pardalos PM (eds) Springer optimization and its applications. Springer, Boston, pp 3-24

Sundar G, Thakur M, Bhattacharyya R, Sarkar S (2016) Stock portfolio selection using Dempster-Shafer evidence theory. J King Saud Univ - Comput Inf Sci. https://doi.org/10.1016/j.jksuci.2016.07.001

Takeda E (2001) A method for multiple pseudo-criteria decision problems. Comput Oper Res 28:1427-1439. https://doi. org/10.1016/S0305-0548(00)00050-2

Thor J, Ding S, Kamaruddin S (2013) Comparison of multi criteria decision making methods from the maintenance alternative selection perspective. Int J Eng Sci 2:27-34

Tiryaki F, Ahlatcioglu M (2005) Fuzzy stock selection using a new fuzzy ranking and weighting algorithm. Appl Math Comput 170:144-157. https://doi.org/10.1016/j.amc.2004.10.092

Touni Z, Makui A, Mohammadi E (2019) A MCDM-based approach using UTA-STRAR method to discover behavioral aspects in stock selection problem. Int J Ind Eng Prod Res. https://doi.org/10.22068/ijiepr.30.1.93

Vakilipour S, Sadeghi-Niaraki A, Ghodousi M, Choi SM (2021) Comparison between multi-criteria decision-making methods and evaluating the quality of life at different spatial levels. Sustain. https://doi.org/10.3390/su13074067

Vanani IR, Emamat MSMM (2019) Analytical review of the applications of multi-criteria decision making in data mining. In: Öner SC, Yüregir OH (eds) Optimizing big data management and industrial systems with intelligent techniques. IGI Global, pp 53-79

Velasquez M, Hester P (2013) An analysis of multi-criteria decision making methods. Int J Oper Res 10:56-66

Verheyden T, De Moor L (2014) Sorting mutual funds with respect to process-oriented social responsibility: A FLOWSORT application. Decis Sci Lett 3:551-562. https://doi.org/10.5267/j.dsl.2014.5.004

Wang H, Kou G, Peng Y (2021) An iterative algorithm to derive priority from large-scale sparse pairwise comparison matrix. IEEE Trans Syst Man Cybern Syst. https://doi.org/10.1109/TSMC.2021.3049604

Xidonas P, Psarras J (2010) A multiple criteria decision-making approach for the selection of stocks. J Oper Res Soc 61:1273-1287. https://doi.org/10.1057/jors.2009.74

Xidonas P, Askounis D, Psarras J (2009a) Common stock portfolio selection: a multiple criteria decision making methodology and an application to the Athens Stock Exchange. In: Operational Research

Xidonas P, Mavrotas G, Psarras I (2009b) A multicriteria methodology for equity selection using financial analysis. Comput Oper Res 36:3187-3203. https://doi.org/10.1016/j.cor.2009.02.009

Xidonas P, Mavrotas G, Krintas T, et al (2012) Multicriteria Portfolio Management. In: Multicriteria portfolio management. Springer, pp 5-21

Yalcin N, Bayrakdaroglu A, Kahraman C (2012) Application of fuzzy multi-criteria decision making methods for financial performance evaluation of Turkish manufacturing industries. Expert Syst Appl. https://doi.org/10.1016/..eswa. 2011.07.024 
Yu D, Kou G, Xu Z, Shi S (2021) Analysis of collaboration evolution in AHP research: 1982-2018. Int J Inf Technol Decis Mak 20:7-36

Yu W (1992) Aide multicritère à la décision dans le cadre de la problématique du tri: concepts, méthodes et applications Zhang J, Kou G, Peng Y, Zhang Y (2021) Estimating priorities from relative deviations in pairwise comparison matrices. Inf Sci (ny). https://doi.org/10.1016/j.ins.2020.12.008

Zitouni T (2014) Construction of a multicriteria model for the assessment of US stocks. Int Rev Manag Bus Res 3:1997-2015

Zopounidis C, Doumpos M, Zanakis S (1999) Stock evaluation using a preference disaggregation methodology. Decis Sci 30:313-336. https://doi.org/10.1111/j.1540-5915.1999.tb01612.x

\section{Publisher's Note}

Springer Nature remains neutral with regard to jurisdictional claims in published maps and institutional affiliations.

Submit your manuscript to a SpringerOpen ${ }^{0}$ journal and benefit from:

- Convenient online submission

- Rigorous peer review

- Open access: articles freely available online

- High visibility within the field

- Retaining the copyright to your article

Submit your next manuscript at $\boldsymbol{\Delta}$ springeropen.com 